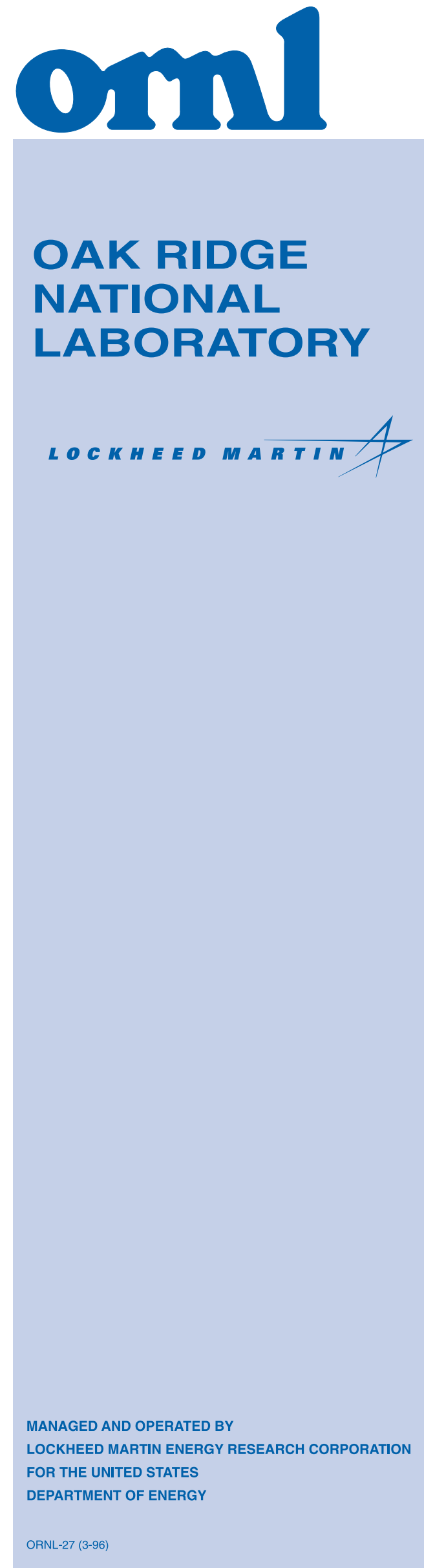

ORNL/TM-13389

\title{
Grout Performance in Support of In Situ Stabilization/ Solidification of the GAAT Tank Sludges
}

\author{
R. D. Spence \\ J. L. Kauschinger*
}

*Ground Environmental Services, Inc. 200 Berry Glen Court

Alpharetta, GA 30202 
This report has been reproduced directly from the best available copy.

Available to DOE and DOE contractors form the Office of Scientific and Technical Information, P.O. Box 62, Oak Ridge, TN 37831; prices available from (615) 576-8401.

Available to the public from the National Technical Information Service, U.S. Department of Commerce, 5285 Port Royal Rd., Springfield, VA 22161.

This report was prepared as an account of work sponsored by an agency of the United States Government. Neither the United States nor any agency thereof, nor any of their employees, makes any warranty, express or implied, or assumes any legal liability or responsibility for the accuracy, completeness, or usefulness of any information, apparatus, product, or process disclosed, or represents that its use would not infringe privately owned rights. Reference herein to any specific commercial product, process, or service by trade name, trademark, manufacturer, or otherwise, does not necessarily constitute or imply its endorsement, recommendation, or favoring by the United States Government or any agency thereof. The views and opinions of authors expressed herein do not necessarily state or reflect those of the United States Government or any agency thereof. 
Chemical Technology Division

\title{
GROUT PERFORMANCE IN SUPPORT OF IN SITU \\ STABILIZATION/SOLIDIFICATION OF THE GAAT TANK SLUDGES
}

\author{
*Ground Environmental Services, Inc. \\ 200 Berry Glen Court \\ Alpharetta, GA 30202
}

R. D. Spence

J. L. Kauschinger*

Date Published-May 1997

\author{
Prepared by the \\ Oak Ridge National Laboratory \\ Oak Ridge, Tennessee 37831-6285 \\ Managed by \\ LOCKHEED MARTIN ENERGY RESEARCH CORP. \\ for the \\ U.S. DEPARTMENT OF ENERGY \\ under contract DE-AC05-96OR22646
}




\section{CONTENTS}

Page

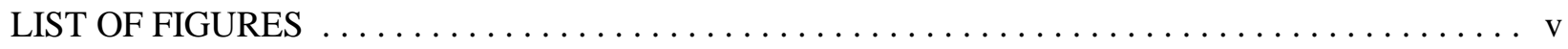

LIST OF TABLES $\ldots \ldots \ldots \ldots \ldots \ldots \ldots \ldots \ldots \ldots \ldots \ldots \ldots \ldots \ldots \ldots \ldots \ldots \ldots \ldots \ldots \ldots \ldots$

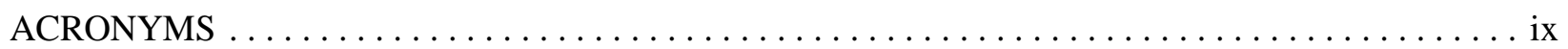

ACKNOWLEDGMENTS $\ldots \ldots \ldots \ldots \ldots \ldots \ldots \ldots \ldots \ldots \ldots \ldots \ldots \ldots \ldots \ldots \ldots \ldots \ldots \ldots$

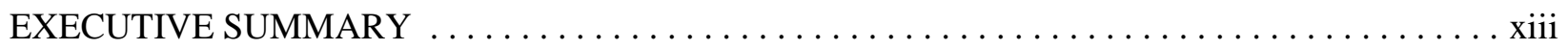

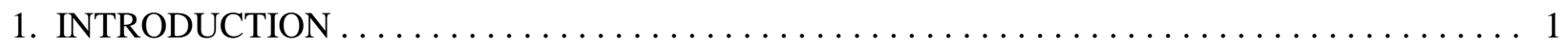

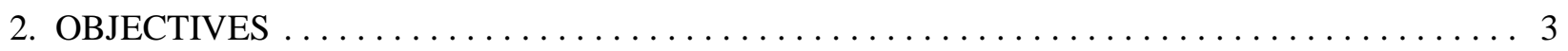

3. TANK CHARACTERISTIC AND CHEMICAL SURROGATE SELECTION $\ldots \ldots \ldots \ldots \ldots$

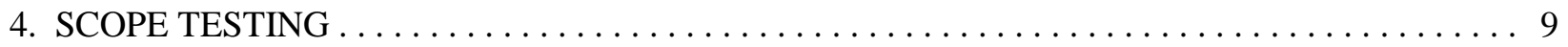

4.1 TANK SELECTION AND MPITM STRATEGY $\ldots \ldots \ldots \ldots \ldots \ldots \ldots \ldots \ldots \ldots \ldots$

4.2 PRELIMINARY WEIGHT-VOLUME CALCULATIONS $\ldots \ldots \ldots \ldots \ldots \ldots \ldots \ldots \ldots 11$

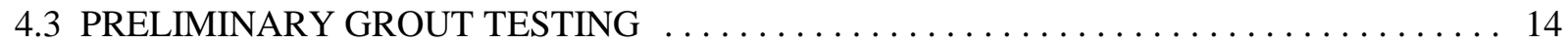

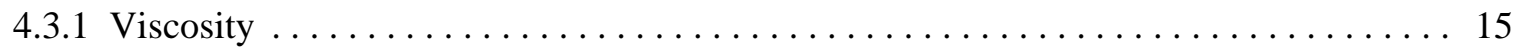

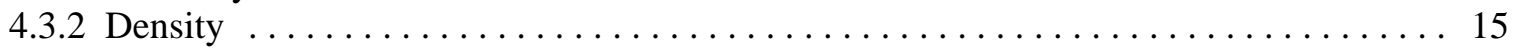

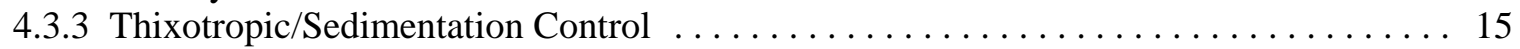

4.4 PRELIMINARY GROUT TESTING RESULTS $\ldots \ldots \ldots \ldots \ldots \ldots \ldots \ldots \ldots \ldots \ldots$

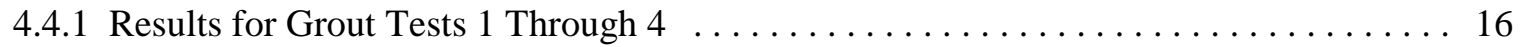

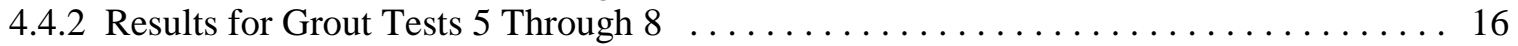

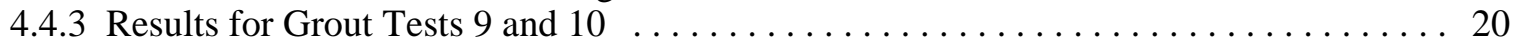

4.4.4 Results for Grout Test 11: Salt Flocculation Test $\ldots \ldots \ldots \ldots \ldots \ldots \ldots \ldots \ldots \ldots$

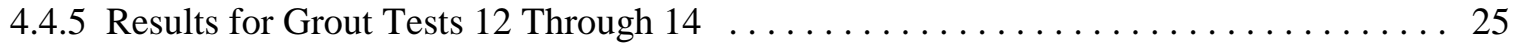

4.5 GROUT/MONOLITH FORMULA FOR LEACHABILITY TESTING . . . . . . . . . . 26

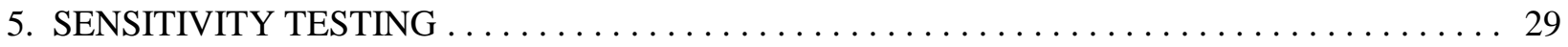

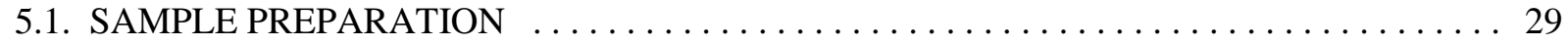

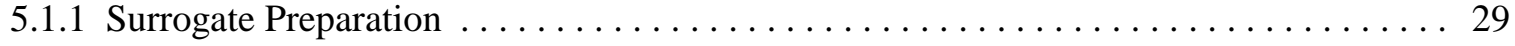

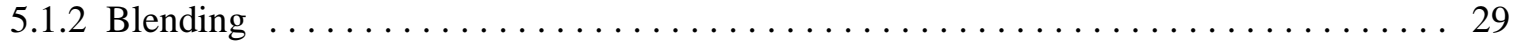

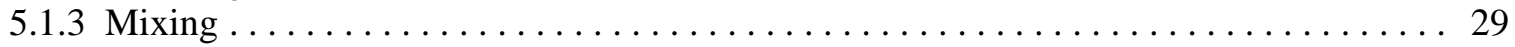

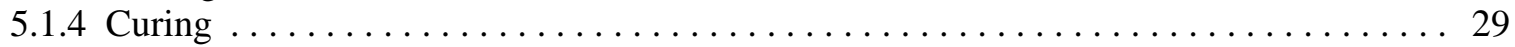

5.2 PERFORMANCE TESTING OF SOLIDIFIED RADIOACTIVE SURROGATE . . . . . . 29

5.3 FINAL MONOLITH SENSITIVITY TESTING $\ldots \ldots \ldots \ldots \ldots \ldots \ldots \ldots \ldots \ldots \ldots \ldots \ldots$

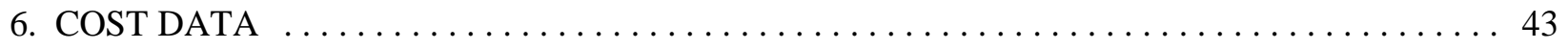

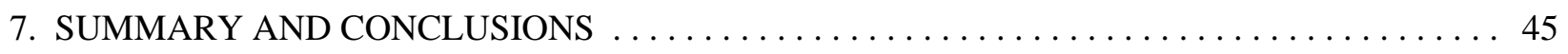

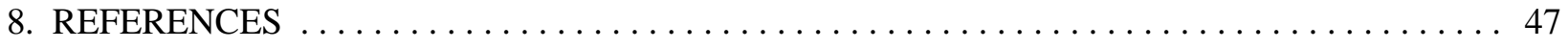




\section{LIST OF FIGURES}

Figure

Page

1 Waste monolith sawed into two pieces: left half is internal core of solidified waste;

right half is outer skin cast against steel shell of B-25 box $\ldots \ldots \ldots \ldots \ldots \ldots \ldots \ldots$

2 Comparison of the percentage of wet sludge in the GAAT solidified monolith for various jet

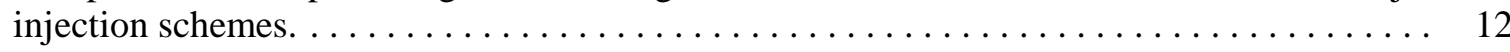

3 Comparison of the amount of freeboard above the GAAT monolith for various jet injection

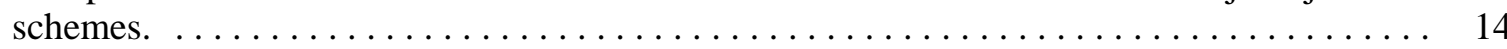

4 Summary of sedimentation study performed for GAAT grout: grout test $6-6 \%$ bentonite,

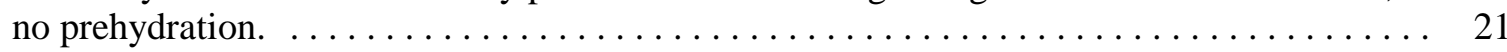

5 Compilation of Fann ${ }^{\mathrm{TM}}$ viscometer readings for GAAT grout: grout test $7-6 \%$ bentonite,

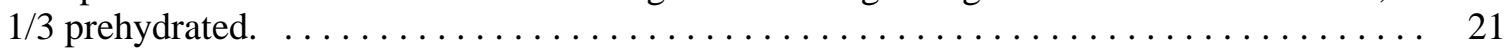

6 Summary of sedimentation study performed for GAAT grout: grout test $7-6 \%$ bentonite,

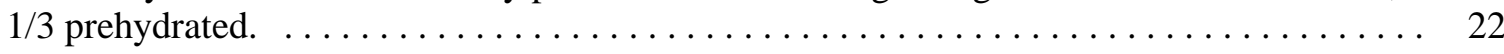

7 Fraction of constituents in monolith, GAAT grout: grout test $7-6 \%$ bentonite,

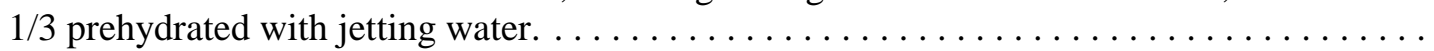

8 Compilation of Fann ${ }^{\mathrm{TM}}$ viscometer readings for GAAT grout: grout test 8-pure gel 8.7\% +

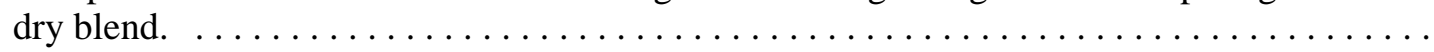

9 Summary of sedimentation study performed for GAAT grout: grout test 8-pure gel $8.7 \%+$

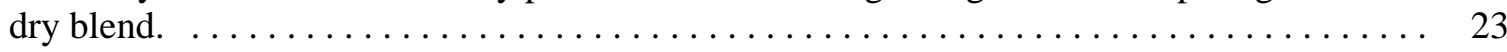

10 Fraction of constituents in monolith, GAAT grout: grout test 8 -pure gel $8.7 \%+$ dry blend. 24

11 Summary of sedimentation study performed for GAAT grout: grout test 11 -pure gel $8.7 \%+$

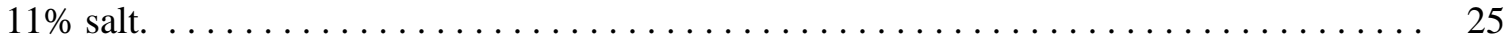

12 Fraction of constituents in monolith, GAAT tank TH-4, grout $13 . \ldots \ldots \ldots \ldots \ldots$

13 Strontium-85 leaching with time for the standard in situ GAAT grout (grout 1 in Table 12). 36

14 Strontium-85 leaching with time for the sensitivity in situ GAAT grouts. $\ldots \ldots \ldots \ldots$

15 Cesium-137 leaching with time for the standard in situ GAAT grout (grout 1 in Table 12). . 38

16 Cesium-137 leaching with time for the sensitivity in situ GAAT grouts. . . . . . . 39

17 Comparison of leach results for ${ }^{85} \mathrm{Sr}$ among GAAT, MVST, IRPC, and CST. . . . . . 40

18 Comparison of leach results for ${ }^{137} \mathrm{Cs}$ among GAAT, MVST, IRPC, and CST. . . . . . 41 


\section{LIST OF TABLES}

Table

Page

$1 \quad$ Summary of surrogate GAAT sludge design $\ldots \ldots \ldots \ldots \ldots \ldots \ldots \ldots \ldots \ldots$

2 Average composition of the GAAT sludges $\ldots \ldots \ldots \ldots \ldots \ldots \ldots \ldots \ldots \ldots \ldots \ldots \ldots \ldots$

3 Estimated quantity of GAAT sludges, sludge density, sludge $\mathrm{pH}$, and weighting factor $\ldots \quad$. 7

4 Summary of target surrogate elemental and ionic concentrations compared with the weighted average and the maximum tank average concentrations $\ldots \ldots \ldots \ldots \ldots \ldots \ldots \ldots$

5 Dry blend composition for hydrofracture and preliminary $\mathrm{MPI}^{\mathrm{TM}}$ calculations $\ldots \ldots \ldots$

6 Calculated components of in situ monolith form using MPI ${ }^{\mathrm{TM}}$ process (GAAT tank TH-4) . . 13

7 Composition of dry blends, jetting slurries, and grouts tested in the scoping tests for an in situ GAAT grout using a sand-water surrogate to simulate the GAAT sludge $\ldots \ldots \ldots \ldots \ldots \quad 17$

$8 \quad$ Measured properties of the jetting slurry and grout for the scoping tests using a sand-water

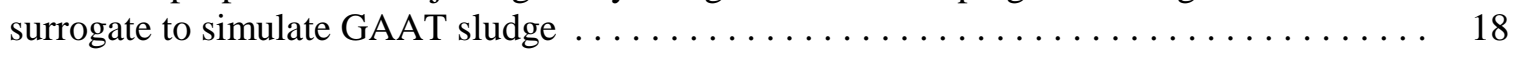

9 Sand distribution in a column of grout from the scoping test grouts $\ldots \ldots \ldots \ldots \ldots$

10 Composition of the in situ monolith for GAAT sludges selected for sensitivity testing:

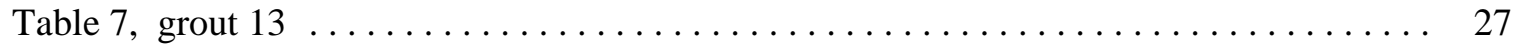

11 Composition of GAAT surrogate sludges for sensitivity testing $\ldots \ldots \ldots \ldots \ldots \ldots$

12 Grout compositions for testing sensitivity of the in situ grout formulation for the GAAT sludges to variations in composition $\ldots \ldots \ldots \ldots \ldots \ldots \ldots \ldots \ldots \ldots \ldots \ldots \ldots \ldots \ldots \ldots \ldots \ldots \ldots \ldots \ldots$

13 Results of performance testing of sensitivity of in situ GAAT grouts $\ldots \ldots \ldots \ldots \ldots$

14 Results of leach testing of sensitivity of in situ GAAT grouts $\ldots \ldots \ldots \ldots \ldots \ldots \ldots$

15 Estimated cost for MPI ${ }^{\mathrm{TM}}$ solidification of one 50 -ft-diam Gunite ${ }^{\mathrm{TM}} \operatorname{tank} \ldots \ldots \ldots$ 


\section{ACRONYMS}

ANSI/ANS

CST

GAAT

IC

ICP

IRPC

LDR

MPI $^{\mathrm{TM}}$

MVST

NRC

ORNL

PVC

RCRA

TBP

TCLP

TIC

TOC

UTS

$\mathrm{W} / \mathrm{S}$
American National Standards Institute/American Nuclear Society

crystalline silicotitanate

Gunite $^{\mathrm{TM}}$ and associated tank

inorganic carbon

Thermo Jarrel Ash ICAP 61E Trace Analyzer

Indian red pottery clay

land disposal restriction

Multi-Point Injection ${ }^{\mathrm{TM}}$

Melton Valley Storage Tank

U.S. Nuclear Regulatory Commission

Oak Ridge National Laboratory

polyvinyl chloride

Resource Conservation and Recovery Act

Tributyl phosphate

Toxicity Characteristic Leaching Procedure

total inorganic carbon

total organic carbon

Universal Treatment Standard

water to solids 


\section{ACKNOWLEDGMENTS}

The authors gratefully acknowledge the financial support and guidance provided by S. D. Van Hoesen, the laboratory work and data collection provided by D. E. Hobson and D. R. Trotter, and the analytical support provided by C. H. Mattus. 


\section{EXECUTIVE SUMMARY}

The Gunite ${ }^{\mathrm{TM}}$ and Associated Tanks (GAATs) were constructed at Oak Ridge National Laboratory (ORNL) between 1943 and 1951 and were used for many years to collect radioactive and chemical wastes generated by ORNL operations. These tanks are currently inactive and have not been used to collect waste solutions and sludges for many years. Varying amounts of the sludge accumulated in these tanks were removed and disposed of through the Hydrofracture Program. ${ }^{1}$ Thus, some tanks are virtually empty, while others still contain significant amounts of sludge and supernatant. The sludges contain a high amount of radioactivity (mainly ${ }^{90} \mathrm{Sr}$ and ${ }^{137} \mathrm{Cs}$ ). Some Resource Conservation and Recovery Act (RCRA) metal concentrations are high enough in the available total constituent analysis for the GAAT sludges to potentially be RCRA hazardous waste. [Some GAAT sludges have been found to be characteristically hazardous for mercury through a Toxicity Characteristic Leaching Procedure (TCLP); therefore, these sludges are presumed to be mixed waste.]

Grouting and vitrification are currently the most likely stabilization/solidification alternatives for mixed wastes. Grouting has been used for decades to stabilize/solidify hazardous and low-level radioactive waste. Vitrification has been used for decades as an alternative for high-level radioactive wastes and has been under development recently as a mixed-waste alternative disposal technology. In situ grouting of the tank sludges using Multi-point injection ${ }^{\mathrm{TM}}$ (MPI $\left.{ }^{\mathrm{TM}}\right)$, a patented, proprietary technique, ${ }^{2}$ is being investigated as a low-cost alternative to (1) moving the sludges to the Melton Valley Storage Tanks for later solidification and disposal, (2) ex situ grouting of the sludges followed by either disposal back into the tanks or containerizing and disposal elsewhere, and (3) vitrification of the sludges. The usual disadvantage of volume increase by grouting does not apply in this case if the grout is disposed of in place in the existing tanks (the current plan is to fill the tanks for structural stability and leave them in place whether the sludge is removed or stabilized in place). Mass balance numerical calculations simulating the MPI ${ }^{\mathrm{TM}}$ jet injection procedure agreed well with actual measured weight-volume data gathered on physical sand surrogate/grout mixtures. Therefore, it appears reasonable that the numerical calculations presented in this report are a good indicator of what will happen in the GAATs.

Based on the work with the surrogate sludges, in situ grouting of the GAAT sludges by MPI ${ }^{\mathrm{TM}}$ can produce grouts with little or no free water that are resistant to solids segregation, that stabilize the RCRA metals within TCLP limits, and that provide excellent leach resistance for the radionuclides. The turbulent mixing caused by the MPI ${ }^{\mathrm{TM}}$ process would ensure that the pretreatment would be homogeneously incorporated into the monolith. (There was evidence of this when solidifying miscellaneous buried waste with a sand cover; essentially the top 12 in. of sand were uniformly incorporated into the monolith). These results must be confirmed with actual hot sludge before final acceptance. The tank sludges can be stabilized at a wet sludge loading of $37 \mathrm{wt} \%$, or less, resulting in a volume increase of $150 \%$, or more, with little or no secondary waste generation. The grout strength is relatively low at $100-500$ psi but is more than strong enough to support tank shells and anticipated overburdens. A strong monolithic solid is not usually a waste acceptance criterion, although a monolith does decrease the surface area available for leaching and consequently improves leach resistance. Grouts can stabilize the RCRA metals, including mercury, a potential problem species for the tank sludges, and pass the TCLP test. The grout selected for sensitivity testing decreased the concentrations of mercury, lead, and chromium in the TCLP extract by orders of magnitude. Despite the high water content, these grouts exhibited excellent leach resistance, with ${ }^{85} \mathrm{Sr}$ and ${ }^{137} \mathrm{Cs}$ leachability indexes in excess of $10{ }^{85} \mathrm{Sr}$ was used in place of ${ }^{90} \mathrm{Sr}$ in laboratory testing). These leach curves exhibit little scatter among them, resulting in the small range of leachability indexes calculated from these data: 10.3 to 10.7 and 10.9 to 11.6 for ${ }^{85} \mathrm{Sr}$ and ${ }^{137} \mathrm{Cs}$, respectively. In general, these leachability indexes are excellent for these relatively soluble radioisotopes. The NRC performance criteria recommend leachability indexes of $>6.0$, meaning that the leach resistance of these grouts exceeds the NRC minimum by four orders of magnitude 
(in terms of the effective diffusion coefficient). Thus, stabilization of the surrogate GAAT sludge in the in situ GAAT grout decreased the TCLP extract concentration by more than a factor of 60,000 for mercury, 30 for lead, and 100 for chromium. In addition, the TCLP extract concentration of uranium decreased from 4,198 to $<0.089 \mathrm{mg} / \mathrm{L}$, a reduction factor of more than 40,000.

None of the properties of this grout proved sensitive to the variations in grout and surrogate sludge compositions tested, except the pumpability of the jetting slurry. It appears that the slag-fly ash grout in this study has very slow cure characteristics. This is an important feature that provides time to remix the jetting slurry or the sludge and grout to form a homogenous monolith. Designing the grout to resist settling of solids made it borderline in the objective test of pumpability. Further refinement or testing may be required to ensure that the designated jetting slurry is pumpable during application of MPI ${ }^{\mathrm{TM}}$ in situ grouting of the tank sludges. A small field test with full-scale equipment is suggested before actual tank remediation. Pumping the proposed jetting slurry through the full-scale equipment is quite different from the laboratory mixing and testing and will reveal any pumping difficulties. If such pumping difficulties exist, then further refinements can be made to the grout formulation.

The cost for MPI ${ }^{\mathrm{TM}}$ solidification of one 50 -ft-diam Gunite ${ }^{\mathrm{TM}}$ tank is estimated at $\$ 500 \mathrm{~K}$, which includes the construction costs, management fees, health physics surveys, and security. 


\section{INTRODUCTION}

The Gunite ${ }^{\mathrm{TM}}$ and associated tanks (GAATs) were constructed at Oak Ridge National Laboratory (ORNL) between 1943 and 1951 and were used for many years to collect radioactive and chemical wastes generated by ORNL operations. These tanks are currently inactive and have not been used to collect waste solutions and sludges for many years. Varying amounts of the sludge accumulated in the tanks were removed and disposed of through the Hydrofracture Program. ${ }^{1}$ Thus, some tanks are virtually empty, while others still contain significant amounts of sludge and supernatant. The sludges contain a high amount of radioactivity (mainly ${ }^{90} \mathrm{Sr}$ and ${ }^{137} \mathrm{Cs}$ ). Some Resource Conservation and Recovery Act (RCRA) metal concentrations are high enough in the available total constituent analysis for the GAAT sludges to potentially be RCRA hazardous waste. [Toxicity Characteristic Leaching Procedures (TCLPs) have shown some GAAT sludges to be characteristically hazardous for mercury; therefore, these sludges are presumed to be mixed waste.]

Grouting and vitrification are currently the most likely stabilization/solidification alternatives for mixed wastes. Grouting has been used for decades to stabilize/solidify hazardous and low-level radioactive waste. Vitrification has been used for decades as an alternative for high-level radioactive waste stabilization and has been under development recently as a mixed-waste alternative disposal technology. In situ grouting of the sludges in the tanks using multi-point injection (MPI ${ }^{\mathrm{TM}}$ ), a patented, proprietary technique, ${ }^{2}$ is being investigated as a low-cost alternative to (1) moving the sludges to the Melton Valley Storage Tanks (MVSTs) for later solidification and disposal, (2) ex situ grouting of the sludges followed by either disposal back in the tanks or containerizing and disposal elsewhere, and (3) vitrification of the sludges. The usual disadvantage of volume increase by grouting does not apply in this case if the grout is disposed of in place in the existing tanks (the current plan is to fill the tanks for structural stability and leave them in place whether the sludge is removed or stabilized in place). 


\section{OBJECTIVES}

High-speed jet injection using the MPI ${ }^{\mathrm{TM}}$ system is an attractive process for in-tank solidification of the sludges because it is remotely operated and because only low-cost disposal hoses and plastic pipes come into contact with the sludge. Before implementing the MPI ${ }^{\mathrm{TM}}$ system, several major questions need to be answered. Regulatory drivers are a critical element of this evaluation; however, the only regulatory issue addressed by this study was the ability of the grout formulations evaluated to pass the TCLP test for the hazardous metals of concern in the waste. The economic and technical drivers for this study relate to the following objectives.

- Identify the specific tank sludges that present a relatively low risk of failure for in situ solidification when compared with the benefits of this process, that is, the low-cost stabilization of RCRA metals and radionuclides.

- Determine whether the fixed volume of the GAATs can accommodate the grout volume created during the MPI ${ }^{\mathrm{TM}}$ process. The ability of the MPI ${ }^{\mathrm{TM}}$ system to homogeneously introduce grout into a waste to form a monolithic structure is a function of the amount of time that the high-speed jets impact and intermix the sludge with grout. Therefore, this objective was addressed by performing weight-volume calculations to estimate the grout volume and final monolith composition. If the tanks do not contain sufficient space for introducing a candidate grout, refinements in the grout formulation can be undertaken.

- Determine acceptable grout viscosities and densities. Constraints on the acceptable grout types for high-speed injection are related to the grout viscosity and density. Laboratory Fann ${ }^{\mathrm{TM}}$ viscometer and density tests were performed as a preliminary screening of several grout types.

- Determine the acceptable thixotropic properties for the candidate grouts. High-speed jet injection creates a suspension of grout and sludge. Once the turbulent action of the jets cease, sludge particles could segregate from the grout. Laboratory tests examined how well the candidate grouts could hold sand particles in suspension while the grout was forming a stable structure.

- Determine the acceptable leachability characteristics and other mechanical properties. Once the candidate grout was shown to be "pumpable" and had the desired thixotropic properties, surrogates of radioactive waste were used for tests on leachability characteristics and other mechanical properties.

- Determine if using the MPI ${ }^{\mathrm{TM}}$ process for in situ solidification of the GAAT sludges is cost effective compared with moving the sludges to the Melton Valley Storage Tanks for later solidification and disposal.

The next section (Sect. 3) discusses the chemical characteristics of the GAATs and the type of chemical surrogate (Table 1) that was used during the leachability tests. This is followed by the experimental work, which, consisted of scope testing (Sect. 4) and sensitivity testing (Sect. 5). The scope testing explored the rheology of the proposed jetting slurries and the settling properties of the proposed grouts using sand-water mixes for the wet sludge. After establishing a jetting slurry and grout with an acceptable rheology and settling properties, the proposed in situ grout formulation was subjected to sensitivity testing for variations in the formulation. 
Table 1. Summary of surrogate GAAT sludge design

\begin{tabular}{|c|c|c|c|}
\hline Compound & Weighted average & $\begin{array}{c}\text { Uncorrected } \\
\text { surrogate: weighted } \\
\text { average }+ \text { maximum } \\
\text { bad actors }\end{array}$ & $\begin{array}{c}\text { Target surrogate after } \\
\text { correction }\end{array}$ \\
\hline \multicolumn{4}{|c|}{ Concentration in wet sludge $(\mathrm{mg} / \mathrm{kg})$} \\
\hline $\mathrm{HgCl}_{2}$ & 177 & 305 & 281 \\
\hline $\mathrm{PbO}$ & 1,032 & 3,749 & 3,458 \\
\hline $\mathrm{Al}(\mathrm{OH})_{3}$ & 35,809 & 35,809 & 33,029 \\
\hline $\mathrm{Ca}(\mathrm{OH})_{2}$ & 17,305 & 17,305 & 15,962 \\
\hline $\mathrm{Fe}_{2} \mathrm{O}_{3}$ & 10,094 & 10,094 & 9,310 \\
\hline $\mathrm{K}_{2} \mathrm{CO}_{3}$ & 4,209 & 4,209 & 3,882 \\
\hline $\mathrm{Mg}(\mathrm{OH})_{2}$ & 5,455 & 5,455 & 5,031 \\
\hline $\mathrm{NaOH}$ & 4,820 & 0 & 0 \\
\hline $\mathrm{Th}\left(\mathrm{NO}_{3}\right)_{4} \cdot 4 \mathrm{H}_{2} \mathrm{O}$ & 56,649 & 56,649 & 52,252 \\
\hline $\mathrm{UO}_{2}\left(\mathrm{NO}_{3}\right)_{2} \cdot 6 \mathrm{H}_{2} \mathrm{O}$ & 83,657 & 83,657 & 77,162 \\
\hline $\mathrm{Na}_{2} \mathrm{Cr}_{2} \mathrm{O}_{7}$ & 1,140 & 3,435 & 3,168 \\
\hline $\mathrm{NaCl}$ & 1,258 & 4,530 & 4,178 \\
\hline $\mathrm{NaF}$ & 3,562 & 13,135 & 12,115 \\
\hline $\mathrm{Na}_{3} \mathrm{PO}_{4}$ & 4,129 & 10,927 & 10,079 \\
\hline $\mathrm{Na}_{2} \mathrm{SO}_{4}$ & 7,643 & 15,822 & 14,593 \\
\hline $\mathrm{Na}_{2} \mathrm{CO}_{3}$ & 38,585 & 38,585 & 35,589 \\
\hline $\mathrm{TBP}^{a}$ & 7,816 & 12,385 & 11,424 \\
\hline \multicolumn{4}{|c|}{ Weight percentage } \\
\hline Solids & 28.3 & 31.6 & 29.2 \\
\hline Water & 70.8 & 70.8 & 70.8 \\
\hline Mass balance & 99.1 & 102.4 & 100.0 \\
\hline Unknown & 0.9 & -2.4 & 0.0 \\
\hline
\end{tabular}

${ }^{a}$ Tributyl phosphate, used to simulate the total organic carbon +100 ppm calcium oxalate. 


\section{TANK CHARACTERISTIC AND CHEMICAL SURROGATE SELECTION}

The composition of the GAAT sludges was estimated using the calculated average values for each tank from the available characterization data. ${ }^{3}$ These data mainly contain the elemental concentrations, although the inorganic carbon (IC) and some anions are reported for the sludge. For the purpose of developing a GAAT surrogate, the IC was assumed to be carbonate, based on past experience with wastewater treatment sludges. Table 2 lists the measured sludge compositions and the mass balance resulting from a weighted average of these measured concentrations. The "Unknown" row in Table 2 indicates that most of the mass was accounted for in the measured elements and anions. Although the available characterization data contained significant unknown masses for the sludges in tanks W-5, W-6, $\mathrm{W}-10$, and TH-4, the measured elements and anions accounted for more than $80 \mathrm{wt} \%$ of the sludge mass without balancing the cation-anion valences or making any assumptions about the compounds present (i.e., assuming that many of the elements were present as oxides and hydroxides likely accounts for the unknown mass). In summary, the measured concentrations accounted for 91, 91, 85, 87, 93, 93, 93, 82, and 87 wt $\%$ of the sludge mass in tanks W-3, W-4, W-5, W-6, W-7, W-8, W-9, W-10, and TH-4, respectively. The weighted average composition listed in Table 2 was obtained by multiplying each tank concentration listed in Table 2 with its weighting factor (see Table 3) and summing the resulting products. The weighting factors are the fraction of the total sludge mass in a given tank. This weighted average composition was the basis for the proposed surrogate GAAT sludge.

The last column in Table 2 lists the sludge concentration of the RCRA metal required to potentially generate a TCLP extract concentration equal to the Universal Treatment Standard (UTS) limit assuming total extraction during the TCLP test. In other words, if the sludge concentration is below the value listed for RCRA metals, it cannot fail the UTS criteria. Mercury was included in the surrogate because TCLPs have proved some of the tank sludges to be characteristically hazardous for mercury. Lead and chromium were also included in the surrogate because of their high concentrations relative to TCLP standards. The $\mathrm{Hg}$ was added as $\mathrm{HgCl}_{2}$, the $\mathrm{Pb}$ as $\mathrm{PbO}$, and the $\mathrm{Cr}$ as $\mathrm{Na}_{2} \mathrm{Cr}_{2} \mathrm{O}_{7}$.

The measured solids concentrations consisted of mainly $\mathrm{U}$, Th, and $\mathrm{Na}$. Uranyl nitrate and thorium nitrate were used for the surrogate, leading to a large excess of nitrate in the surrogate compared to the nitrate measured in the tank sludges. Sodium salts were used in the surrogate for the anions other than nitrate (chloride, fluoride, phosphate, and sulfate) measured in the sludges. Potassium and sodium carbonate were used in the surrogate to supply the desired quantity of inorganic carbon. The remaining major constituents ( $\mathrm{Al}, \mathrm{Ca}, \mathrm{Fe}$, and $\mathrm{Mg}$ ) were added to the surrogate as hydroxides or oxides. Table 1 summarizes the design of the surrogate GAAT sludge. The first column lists the compounds used for the relevant species measured in the tank sludges. The second column lists the concentrations of these compounds needed in the wet sludge for the weighted average concentrations of the relevant species. These listed concentrations are $0.8 \mathrm{wt} \%$ short of accounting for $100 \%$ of the wet sludge mass. The third column lists a combination of the maximum concentrations of the average tank concentration for the bad actors [the RCRA metals $(\mathrm{Hg}, \mathrm{Pb}$, and $\mathrm{Cr}$ ), chloride, fluoride, phosphate, sulfate, and total organic carbon (TOC) or tributyl phosphate (TBP)] plus the weighted average concentrations. Maximizing the bad actor concentrations made the total mass exceed $100 \%$ of the wet sludge mass despite allowing the concentration for the sodium floater compound $(\mathrm{NaOH})$ to drop to zero; hence, this column is designated "Uncorrected surrogate." The last column of Table 1 lists the target concentrations after correcting all of the masses to total $100 \%$ and is the surrogate GAAT sludge composition used for this study. Table 4 lists the elemental and ionic composition of this surrogate and compares the surrogate concentrations to the weighted average and maximum tank average concentrations. 
Table 2. Average composition of the GAAT sludges

\begin{tabular}{|c|c|c|c|c|c|c|c|c|c|c|c|}
\hline & \multicolumn{9}{|c|}{ Tank } & \multirow{2}{*}{$\begin{array}{l}\text { Weighted } \\
\text { average }\end{array}$} & \multirow{2}{*}{$\begin{array}{c}20 \times \text { TCLP } \\
\text { UTS }(\mathrm{mg} / \mathrm{kg})\end{array}$} \\
\hline & $\mathrm{W}-3$ & W-4 & W-5 & W-6 & W-7 & $\mathrm{W}-8$ & W-9 & $\mathrm{W}-10$ & TH-4 & & \\
\hline \multicolumn{12}{|c|}{ Concentrations of metals in the wet sludge $(\mathrm{mg} / \mathrm{kg})$} \\
\hline $\mathrm{Ag}$ & 24 & 25 & & 9 & 4 & & & 5 & & 4 & 6 \\
\hline As & & & 1 & 1 & & & & & 4 & 1 & 100 \\
\hline $\mathrm{Ba}$ & 6 & 9 & 65 & 176 & 81 & 41 & 101 & 156 & 11 & 90 & 152 \\
\hline $\mathrm{Cd}$ & 1 & 4 & 4 & 7 & & 5 & 3 & 4 & 2 & 3 & 4 \\
\hline $\mathrm{Cr}$ & 336 & 228 & 1,273 & 1,363 & 198 & 259 & 120 & 169 & 281 & 452 & 17 \\
\hline $\mathrm{Hg}$ & 15 & 24 & 104 & 78 & 151 & 184 & 67 & 225 & 7 & 130 & 1 \\
\hline $\mathrm{Ni}$ & 6 & 11 & 104 & 151 & 33 & 120 & 73 & 130 & 43 & 92 & 100 \\
\hline $\mathrm{Pb}$ & 10 & 16 & 283 & 3,480 & 40 & 1,370 & 496 & 700 & & 958 & 7 \\
\hline $\mathrm{Tl}$ & & & & 36 & & & & & & 5 & 2 \\
\hline $\mathrm{Al}$ & 17,582 & 4,749 & 15,767 & 10,877 & 4,994 & 9,993 & 8,847 & 31,067 & 2,970 & 12,386 & \\
\hline B & 3 & 5 & 44 & 10 & 24 & 19 & 7 & 5 & 4 & 15 & \\
\hline $\mathrm{Be}$ & & 11 & 1 & & 2 & 11 & 7 & 7 & 2 & 5 & 0.3 \\
\hline $\mathrm{Ca}$ & 9,560 & 1,251 & 13,400 & 29,067 & 1,322 & 8,073 & 6,150 & 9,557 & 1,520 & 9,361 & \\
\hline Co & 4 & 5 & & 12 & & 3 & 3 & 5 & & 3 & \\
\hline $\mathrm{Cu}$ & 26 & 23 & 33 & 44 & 94 & 56 & 48 & 78 & 18 & 58 & \\
\hline $\mathrm{Fe}$ & 1,110 & 963 & 17,667 & 12,950 & 3,618 & 6,420 & 3,207 & 7,770 & 3,477 & 7,060 & \\
\hline K & 338 & 307 & 418 & 826 & 9,942 & 1,430 & 2,987 & 3,250 & 826 & 3,255 & \\
\hline $\mathrm{Mg}$ & 585 & 235 & 3,620 & 1,459 & 279 & 7,360 & 767 & 1,167 & 319 & 2,257 & \\
\hline $\mathrm{Mn}$ & 66 & 30 & 413 & 884 & 73 & 135 & 146 & 201 & 33 & 247 & \\
\hline $\mathrm{Na}$ & 11,607 & 19,450 & 34,900 & 40,700 & 49,020 & 8,300 & 6,340 & 13,033 & 29,333 & 26,364 & \\
\hline $\mathrm{Si}$ & 509 & 234 & & 3,360 & & & & & 223 & 528 & \\
\hline $\mathrm{Sr}$ & 24 & 11 & 31 & 61 & 10 & 47 & 39 & 55 & 12 & 36 & \\
\hline Th & 1,740 & 3,740 & 2,928 & 695 & 4,096 & 13,483 & 5,970 & 6,943 & 154,000 & 23,808 & \\
\hline $\mathrm{U}$ & 72,733 & 122,500 & 15,774 & 39,287 & 100,660 & 5,563 & 19,167 & 11,817 & 38,800 & 39,656 & \\
\hline V & & & & & 2 & 5 & & & & 1 & 5 \\
\hline $\mathrm{Zn}$ & 11 & 10 & 29 & 203 & 34 & 91 & 56 & 112 & 31 & 84 & 106 \\
\hline \multicolumn{12}{|c|}{ Anions $(\mathrm{mg} / \mathrm{kg})$} \\
\hline Bromide & & & & & 103 & 9 & 7 & 21 & & 26 & \\
\hline Chloride & & & 73 & 156 & 2,748 & 423 & 138 & 571 & & 763 & \\
\hline Fluoride & 21 & 21 & 1,973 & 5,943 & 2,232 & 266 & 155 & 378 & 398 & 1,612 & \\
\hline Nitrate & 87 & 1,507 & 554 & 10,823 & 35,960 & 2,590 & 436 & 5,490 & 19,409 & 12,574 & \\
\hline Phosphate & 2,040 & 1,217 & 3,139 & 6,330 & 4,643 & 276 & 2,960 & 267 & 218 & 2,392 & \\
\hline Sulfate & 457 & 1,887 & 291 & 7,867 & 7,720 & 3,683 & 536 & 2,197 & 10,700 & 5,169 & \\
\hline $\begin{array}{l}\text { Carbonate } \\
(\text { TIC })^{a}\end{array}$ & 7,421 & 8,446 & 9,480 & 19,605 & 23,403 & 30,300 & 9,445 & 20,125 & 48,726 & 24,344 & \\
\hline Total & 126,320 & 166,920 & 122,368 & 196,460 & 251,486 & 100,514 & 68,278 & 115,504 & $\mathbf{3 1 1 , 3 6 7}$ & 173,740 & \\
\hline
\end{tabular}


Table 2 (continued)

\begin{tabular}{|c|c|c|c|c|c|c|c|c|c|c|c|}
\hline & \multicolumn{9}{|c|}{ Tank } & \multirow{2}{*}{$\begin{array}{c}\text { Weighted } \\
\text { average }\end{array}$} & \multirow{2}{*}{$\begin{array}{c}20 \times \text { TCLP } \\
\text { UTS }(\mathrm{mg} / \mathrm{kg})\end{array}$} \\
\hline & W-3 & W-4 & W-5 & W-6 & W-7 & W-8 & W-9 & W-10 & TH-4 & & \\
\hline \multicolumn{12}{|c|}{$w t \%$} \\
\hline $\begin{array}{l}\text { Total } \\
\text { solids }\end{array}$ & 12.6 & 16.7 & 12.2 & 19.6 & 25.1 & 10.1 & 6.8 & 11.6 & 31.1 & 17.4 & \\
\hline Water & 78.0 & 73.7 & 72.8 & 67.0 & 67.3 & 81.8 & 85.4 & 70.3 & 54.9 & 70.8 & \\
\hline $\mathrm{TOC}^{b}$ & 0.5 & 0.1 & 0.1 & 0.6 & 0.1 & 0.7 & 0.3 & 0.4 & 0.7 & 0.4 & \\
\hline Total & 91.1 & 90.5 & 85.1 & 87.2 & 92.6 & 92.5 & 92.5 & 82.3 & 86.7 & 88.6 & \\
\hline Unknown & 8.9 & 9.5 & 14.9 & 12.8 & 7.4 & 7.5 & 7.5 & 17.7 & 13.3 & 11.4 & \\
\hline
\end{tabular}

Table 3. Estimated quantity of GAAT sludges, sludge density, sludge $\mathrm{pH}$, and weighting factor

\begin{tabular}{|c|c|c|c|c|c|c|c|c|c|c|}
\hline & \multicolumn{9}{|c|}{ Tank } & \multirow[b]{2}{*}{ Total } \\
\hline & W-3 & W-4 & W-5 & W-6 & W-7 & W-8 & W-9 & W-10 & TH-4 & \\
\hline $\begin{array}{l}\text { Sludge } \\
\text { volume } \\
\text { (gal) }\end{array}$ & 628 & 1,313 & 3,422 & 7,037 & 8,812 & 10,309 & 2,861 & 9,298 & 5,452 & 49,132 \\
\hline $\begin{array}{l}\text { Calculated } \\
\text { sludge mass } \\
\text { (lb) }\end{array}$ & 5,608 & 14,025 & 33,411 & 74,579 & 100,745 & 100,653 & 28,889 & 93,110 & 60,966 & 511,986 \\
\hline $\begin{array}{l}\text { Weighting } \\
\text { factor } \\
(\text { wt } \%)^{a}\end{array}$ & 1.1 & 2.7 & 6.5 & 14.6 & 19.7 & 19.7 & 5.6 & 18.2 & 11.9 & 100.0 \\
\hline $\begin{array}{l}\text { Density } \\
(\mathrm{g} / \mathrm{mL})\end{array}$ & 1.07 & 1.28 & 1.17 & 1.27 & 1.37 & 1.17 & 1.21 & 1.20 & 1.34 & \\
\hline $\mathrm{pH}$ & 11 & 11 & $b$ & 11 & 10 & 9 & 10 & 11 & 9 & \\
\hline
\end{tabular}

${ }^{a}$ Calculated sludge mass in a given tank divided by the total sludge mass multiplied by 100 .

${ }^{b}$ No data available. 
Table 4. Summary of target surrogate elemental and ionic concentrations compared with the weighted average and the maximum tank average concentrations

\begin{tabular}{|c|c|c|c|}
\hline Species & $\begin{array}{l}\text { Target surrogate } \\
\text { concentration }\end{array}$ & $\begin{array}{l}\text { Ratio of surrogate } \\
\text { to weighted average }\end{array}$ & $\begin{array}{c}\text { Ratio of surrogate to } \\
\text { maximum tank } \\
\text { average }\end{array}$ \\
\hline \multicolumn{4}{|c|}{ Cations ( $\mathrm{mg} / \mathrm{kg}$ ) } \\
\hline $\mathrm{Hg}$ & 208 & 1.59 & 0.92 \\
\hline $\mathrm{Pb}$ & 3,210 & 3.35 & 0.92 \\
\hline $\mathrm{Al}$ & 11,424 & 0.92 & 0.37 \\
\hline $\mathrm{Ca}$ & 8,634 & 0.92 & 0.30 \\
\hline $\mathrm{Fe}$ & 6,512 & 0.92 & 0.37 \\
\hline K & 3,002 & 0.92 & 0.30 \\
\hline $\mathrm{Mg}$ & 2,082 & 0.92 & 0.28 \\
\hline $\mathrm{Na}$ & 35,001 & 1.33 & 0.71 \\
\hline Th & 21,960 & 0.92 & 0.14 \\
\hline $\mathrm{UO}_{2}$ & 41,495 & 0.92 & 0.30 \\
\hline Total & $\mathbf{1 3 3 , 5 2 7}$ & 1.02 & 0.30 \\
\hline \multicolumn{4}{|c|}{ Anions (mg/kg) } \\
\hline $\mathrm{Cr}_{2} \mathrm{O}_{7}$ & 2,612 & 2.78 & 0.92 \\
\hline Chloride & 2,535 & 3.32 & 0.92 \\
\hline Fluoride & 5,482 & 3.40 & 0.92 \\
\hline Nitrate & 42,528 & 3.38 & 1.18 \\
\hline Phosphate & 5,839 & 2.44 & 0.92 \\
\hline Sulfate & 9,869 & 1.91 & 0.92 \\
\hline Carbonate & 22,454 & 0.92 & 0.46 \\
\hline Total & 127,474 & 2.67 & 1.13 \\
\hline Overall total & 261,001 & 1.46 & 0.47 \\
\hline
\end{tabular}




\section{SCOPE TESTING}

\subsection{TANK SELECTION AND MPITM STRATEGY}

The GAATs selected as candidates for in-tank solidification are designated as tanks W-3, W-4, W-5, W-6, and TH-4 on Tables 2 and 3. These tanks were selected by the GAAT Task Committee because they represent relatively small sludge volumes and chemical inventories. The majority of the sludge in these tanks had been exhumed and injected into deep rock formations at Waste Area Group 10, the Hydrofracture Facility. The grout used for this deep injection was essentially a cement-fly ash grout with smaller proportions of Indian red pottery clay (IRPC, illitic clay) and attapulgite. The exact proportions used are summarized in the second column of Table 5, "Hydrofracture blend." This basic grout was modified for this study to include slag as a primary constituent since slag is helpful in immobilizing the RCRA metals contained in the sludge. The slag required a reduction in the amount of cement in the grout formulation. This reduction was acceptable since a high-strength monolith is not required for long-term structural stability of the GAATs. The basic fly ash-slag grout formulation used during the preliminary $\mathrm{MPI}^{\mathrm{TM}}$ calculations is summarized in the last column of Table 5.

Table 5. Dry blend composition for hydrofracture and preliminary MPI ${ }^{\mathrm{TM}}$ calculations

\begin{tabular}{lcc}
\hline & \multicolumn{2}{c}{ Composition (wt \%) } \\
\cline { 2 - 3 }$(1)$ & Hydrofracture blend & $\begin{array}{c}\text { Blend basis for MPITM } \\
\text { calculations } \\
(3)\end{array}$ \\
\hline Type I-II Portland cement & 38.35 & 15.00 \\
Ground granulated blast furnace slag & 0.00 & 35.00 \\
Class F fly ash & 38.35 & 35.00 \\
IRPC & 8.00 & 15.00 \\
Attapulgus 150 ground clay & 15.30 & 0.00 \\
\hline
\end{tabular}

The MPI ${ }^{\mathrm{TM}}$ strategy for solidifying the GAAT sludge has been presented to Lockheed Martin Energy Research Corp. as an internal, proprietary report that is not available for public dissemination. In general, the MPI ${ }^{\mathrm{TM}}$ process uses multiple jetting tools submerged into the sludge. The interaction of multiple jets cuts the waste and creates a massive turbulent action of the grout and sludge, thus the term Multi-Point Injection (MPI $\left.{ }^{\mathrm{TM}}\right)$. The turbulence created by the multiple jets homogeneously mixes the grout and sludge.

Data on using the MPI ${ }^{\mathrm{TM}}$ process to solidify waste are limited. However, the data that are available were obtained from solidification of a highly robust waste form. This waste was miscellaneous solid waste deposited into shallow pits and B- 25 boxes. The waste was mostly contained in steel drums, plastic bags, and cardboard drums and boxes covered in plastic shrink wrap. The MPI ${ }^{\mathrm{TM}}$ system was able to form homogeneous, low-conductivity solidified monoliths of the waste. ${ }^{2}$ The solidified monolith (Fig. 1) had measured conductivities of around 1.0 to $10^{-7} \mathrm{~cm} / \mathrm{s}$. It is believed that the miscellaneous solid waste is a more difficult material to solidify homogeneously than the GAAT sludges and that the MPI ${ }^{\mathrm{TM}}$ system can perform with similar success within the GAATs. The major unknown is the efficiency with which the multiple jets can intermix the grout and sludge. In the case of miscellaneous solid waste, the volume of grout injected varied from 50 to $150 \%$ of the total volume that the waste occupied (i.e., solids, liquids, and void space in the solid matrix and tank in the tank proper). Therefore, in an attempt to be 


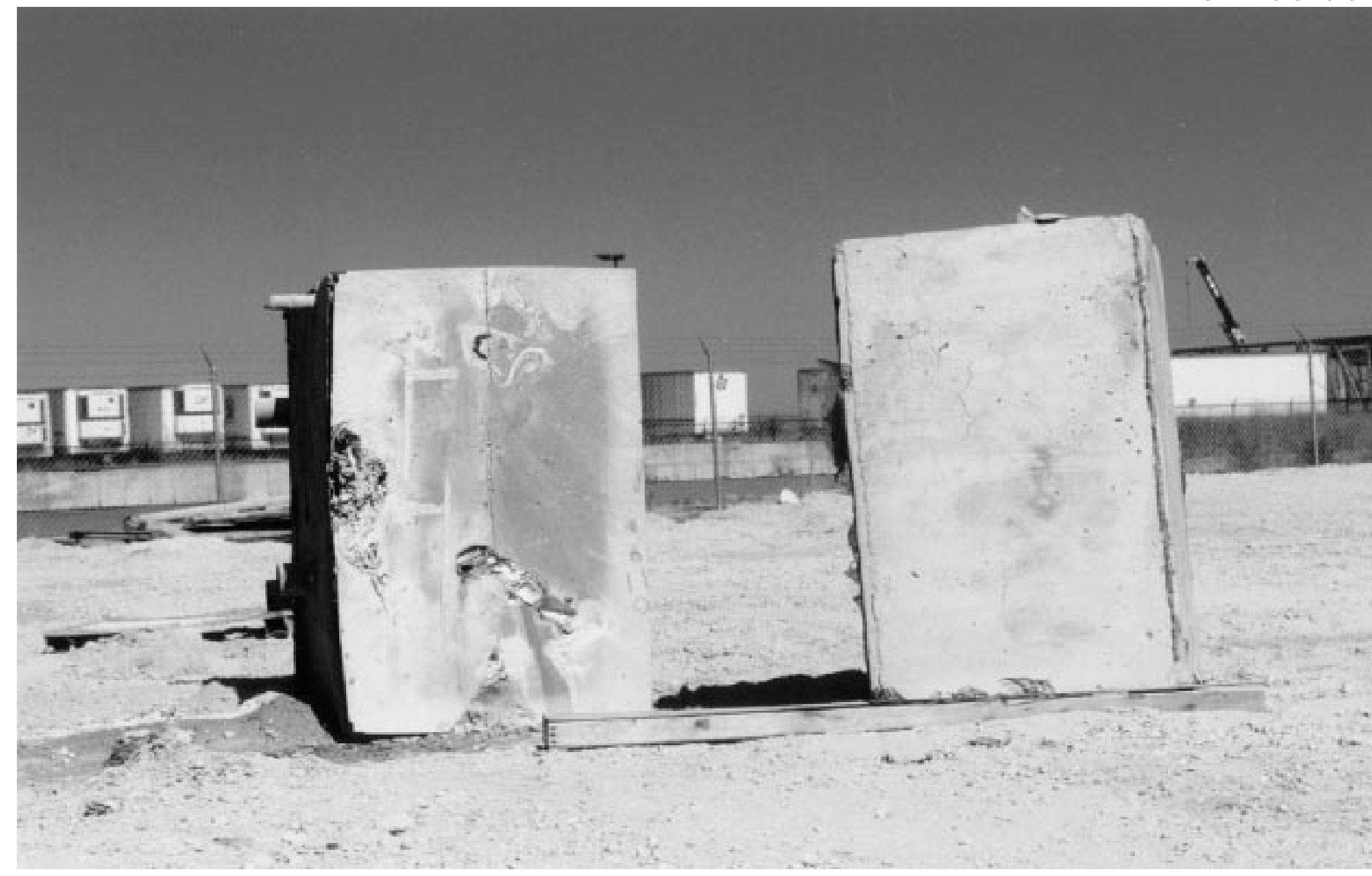

Fig. 1. Waste monolith sawed into two pieces: left half is internal core of solidified waste; right half is outer skin cast against steel shell of B-25 box. Monolith was formed using the MPI ${ }^{\mathrm{TM}}$ process. 
exceptionally conservative, the MPI ${ }^{\mathrm{TM}}$ calculations for the GAATs used grout volumes that varied from $250 \%$ (tank TH-4) up to $1000 \%$ (the other four tanks) of the sludge volume. A logical assumption is that this large grout volume would be sufficient for homogenous mixing of the grout and waste, that is, using five times more grout to homogenously mix a sludge that is considered less robust than highly containerized buried waste.

The actual amount of grout required to homogeneously intermix solidification agents and the tank sludge can be better evaluated in a small field trial using physical surrogates. A letter report related to performing an MPI ${ }^{\mathrm{TM}}$ field trial covers some of the testing that would allow selection of an optimum grout volume. ${ }^{4}$ It is believed that the calculations described in the next section (Sect. 4.2) are conservative and represent an extreme of overinjection to ensure homogeneous mixing of grout and sludge.

\subsection{PRELIMINARY WEIGHT-VOLUME CALCULATIONS}

The sludge volumes and geometry for each of the five candidate GAATs (W-3, W-4, W-5, W-6, and $\mathrm{TH}-4)$ were entered into a spreadsheet program for calculating the weight-volumes of the grout injected and the final proportions of the monolith. Four scenarios were examined during the preliminary numerical studies and involved the following.

1. (Run 1) MPITM jetting of the basic grout (Table 5, column 3) in an attempt to leave the minimum freeboard within the tank. For this report, freeboard is defined as the vertical distance between the top of the monolith and the connection between the vertical wall and the dome of the Gunite ${ }^{\mathrm{TM}} \operatorname{tank}$ (i.e., additional space is available in the tank dome). It was assumed that the supernatant that currently resides above the sludge was pumped down to a 6-in. level before injection.

2. (Run 2) MPITM jetting of the basic grout in an attempt to leave the maximum freeboard within the tank. It was assumed that the supernatant was pumped down to the interface of the sludge (i.e., there would be no remaining supernatant except for interstitial amounts).

Because the sludge is relatively thin (from a few inches to tens of inches in tank TH-4), it was decided to examine the potential of adding a dry blend of slag and fly ash as a pretreatment to the sludge. This would be accomplished by mechanically stowing dry blend onto the surface of the sludge. The mechanically stowed slag and fly ash would be blended into the final monolith during the MPITM process, that is, similar to the 12 in. of sand above the waste solidified in the B-25 box (see Fig. 1). The slag-fly ash pretreatment has the added benefit of increasing the solids content of the monolith without increasing the water content. Therefore, two additional numerical analyses were performed to supplement the first two analyses:

3. (Run 3) MPI ${ }^{\mathrm{TM}}$ jetting of the basic grout plus the addition of slag and fly ash as a pretreatment in an attempt to leave the minimum freeboard within the tank with 6 in. of supernatant left in the tank.

4. (Run 4) MPITM jetting of the basic grout plus the pretreatment in an attempt to leave the maximum freeboard within the tank. It was assumed that all the supernatant was removed from the tank.

The most important results extracted from the calculations were related to (1) the maximum proportion of wet sludge within the monolith (waste loading) and (2) the amount of freeboard remaining within the tank after the injection. Figure 2 shows the waste loading results for each of the five tanks. For the 20 calculations summarized in Fig. 2, the results produced waste loading that was typically at $15 \%$ and below (i.e., 15 of the 20 values were below $15 \%$, with about 12 of the 20 values below $10 \%$ ). These percentages are exceptionally low when compared with typical ex situ solidification, wherein waste loadings of 50\% and higher are common. The highest waste loading (35\%) was calculated for tank TH-4. 


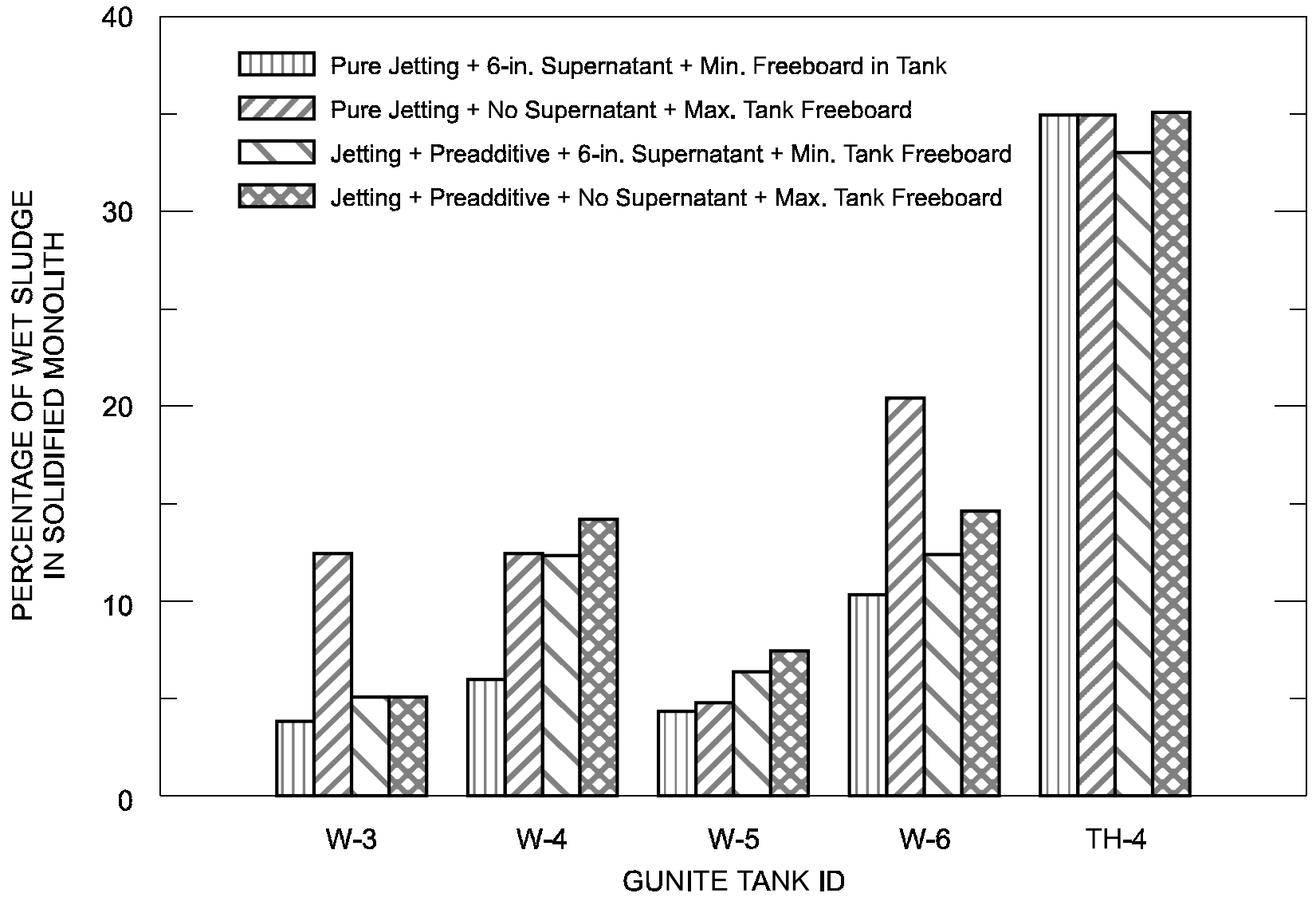

Fig. 2. Comparison of the percentage of wet sludge in the GAAT solified monolith for various jet injection schemes.

Since the waste loading for tank TH-4 was the greatest, it is of interest to discuss the final proportions of the various constituents in the monolith. The specific percentages of cement, slag, fly ash, clay, wet sludge, and liquid (supernatant plus injection water) in the final monolith estimated for tank TH-4 are summarized in Table 6. The first two columns of numerical data represent the results from jet injection only, which correspond to Runs 1 and 2. In general, the dry components of grout represent about 37 to $41 \%$ of the monolith, with the wet sludge at $35 \%$, and the supernatant and injected water at about $28 \%$. When dry slag $(21,600 \mathrm{lb})$ and fly ash $(14,400 \mathrm{lb})$ were stowed atop the wet sludge (Runs 3 and 4), the dry components of the monolith increased to nearly $50 \%$ of the total weight (with slag representing about $22 \%$ and fly ash about $17 \%$ ). Obviously, mechanical stowing of slag and fly ash as a pretreatment to MPI ${ }^{\mathrm{TM}}$ is an attractive (i.e., inexpensive and easy to perform) means of increasing the solids content of the final monolith. Typically, as the solids increase there is a decrease in hydraulic conductivity and the leachability of the monolith is also often reduced.

The amount of freeboard above the monolith after solidification was also calculated for each of the four runs performed for the five tanks (20 analyses). The results from the calculations (Fig. 3) indicate that for tanks W-3, W-4, W-5, and W-6, at least 90 in. (and up to 120 in.) of additional freeboard remain after injection. Therefore, for these tanks the field controls over the injection are not severe because there is plenty of room for additional injection (if required). Also, if the low waste loading (15\%) for these tanks needs to be reduced further, there is plenty of capacity to accommodate additional dilution of the wet sludge. 
Table 6. Calculated components of in situ monolith form using MPI ${ }^{\mathrm{TM}}$ process (GAAT tank TH-4)

\begin{tabular}{|c|c|c|c|c|}
\hline \multicolumn{5}{|c|}{ Basis for MPI ${ }^{\mathrm{TM}}$ calculation } \\
\hline Method of blend addition & Pure jetting & Pure jetting & $\begin{array}{l}\text { Preaddition + } \\
\text { jetting }\end{array}$ & $\begin{array}{l}\text { Preaddition }+ \\
\text { jetting }\end{array}$ \\
\hline Supernatant grouted & $\begin{array}{l}\text { 6-in. layer above } \\
\text { sludge layer }\end{array}$ & None & $\begin{array}{l}\text { 6-in. layer above } \\
\text { sludge layer }\end{array}$ & None \\
\hline Freeboard & Minimum & Maximum & Minimum & Maximum \\
\hline \multicolumn{5}{|l|}{ Quantity preadded (lb) } \\
\hline Slag & 0 & 0 & 21,600 & 21,600 \\
\hline Fly ash & 0 & 0 & 14,400 & 14,400 \\
\hline \multicolumn{5}{|c|}{ Predictions calculated for in situ MPI ${ }^{\mathrm{TM}}$ grouting } \\
\hline \multicolumn{5}{|l|}{$\begin{array}{l}\text { Final monolithic structure } \\
\text { (wt \%) }\end{array}$} \\
\hline Cement & 5.6 & 6.1 & 4.0 & 4.2 \\
\hline Slag & 13.0 & 14.2 & 20.8 & 21.9 \\
\hline Fly ash & 13.0 & 14.2 & 17.0 & 17.9 \\
\hline IRPC & 5.6 & 6.1 & 4.0 & 4.2 \\
\hline $\begin{array}{l}\text { Supernate + injection } \\
\text { water }\end{array}$ & 27.7 & 24.4 & 21.1 & 16.8 \\
\hline Wet sludge $^{a}$ & 35.0 & 35.0 & 33.1 & 35.0 \\
\hline Grout vol./waste vol. & 2.63 & 2.56 & 2.62 & 2.41 \\
\hline Water/solids & 1.02 & 0.89 & 0.74 & 0.65 \\
\hline Free water $(\operatorname{vol} \%)^{b}$ & 10.0 & 3.3 & 0.0 & 0.0 \\
\hline 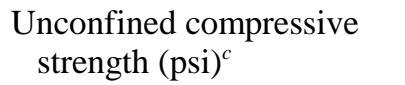 & 200 & 200 & 750 & 750 \\
\hline
\end{tabular}

${ }^{a}$ Water content of wet sludge was assumed to be $65 \mathrm{wt} \%$.

${ }^{b}$ Estimated value from individual component's affinity to absorb water.

${ }^{c}$ Unconfined compressive strength estimated from test program conducted on plastic concrete for the U.S. Army Corps of Engineers; Kauschinger and Perry, Waterways Experiment Station Technical Report REMR-GT-15, 1991. 


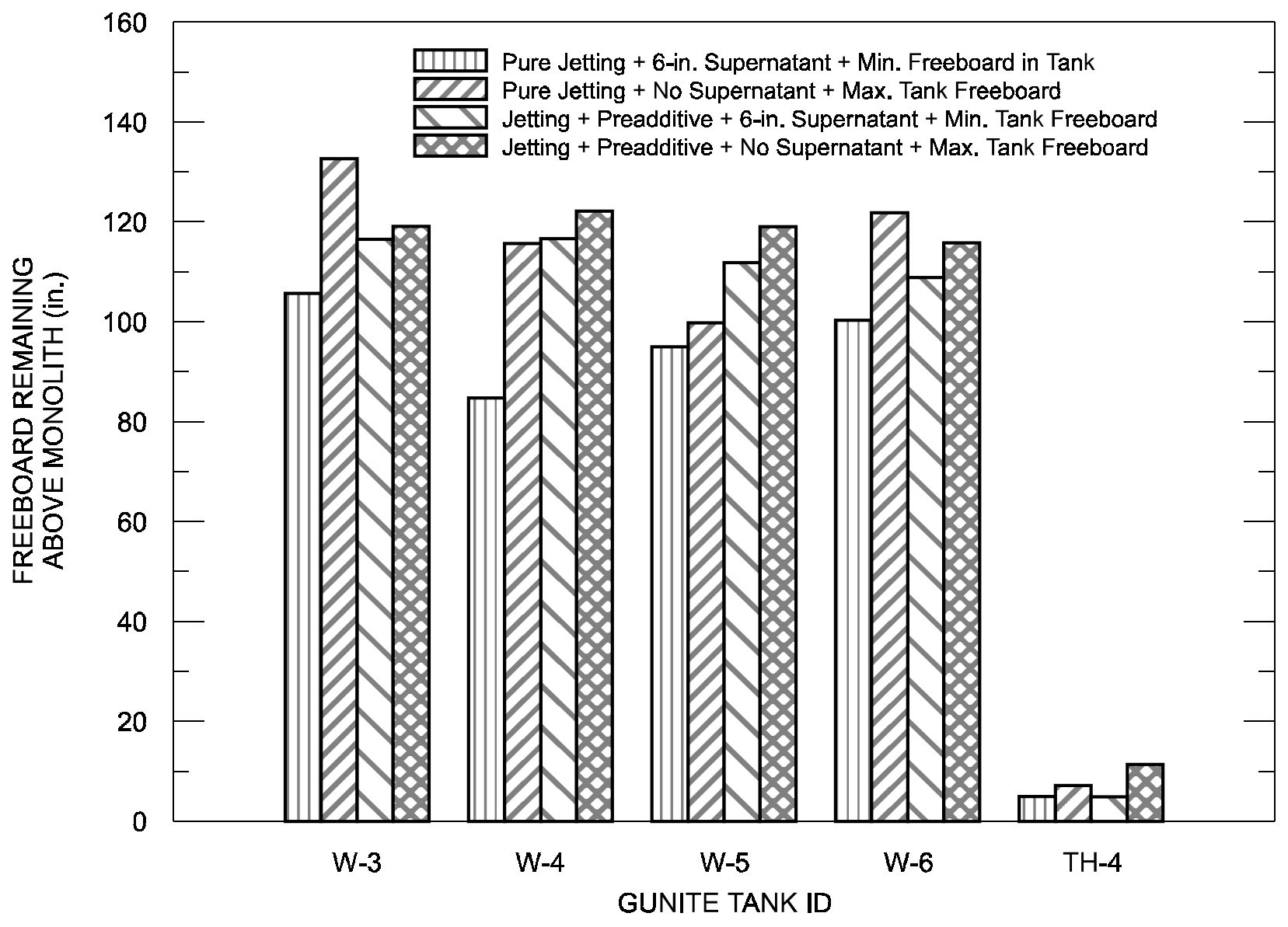

Fig. 3. Comparison of the amount of freeboard above the GAAT monolith for various jet injection schemes.

In contrast to tanks W-3 through W-6, calculations for tank TH-4 indicate that there would be about 7 to $11 \mathrm{in.} \mathrm{of} \mathrm{freeboard} \mathrm{remaining} \mathrm{after} \mathrm{injection.} \mathrm{It} \mathrm{appears} \mathrm{that} \mathrm{because} \mathrm{tank} \mathrm{TH-4} \mathrm{would} \mathrm{develop} \mathrm{the}$ greatest waste loading (35\%) and have the smallest amount of freeboard remaining after injection, any additional study should focus on this tank. It should be reemphasized that the grout volume calculated for injection (250\% of the sludge volume) into tank TH-4 is probably much greater than what is required to homogeneously mix the grout and sludge. The actual amount of grout required needs to be validated by a field trial in which the tank characteristics for TH-4 are used. ${ }^{4}$

\subsection{PRELIMINARY GROUT TESTING}

The preliminary formulation for the fly ash-slag grout used in the weight-volume calculations (see Table 5 for proportions) needs to be refined because the numerical calculations could not evaluate the thixotropic properties of the grout, which are important to ensure that the sludge particles and grout do not segregate after the MPI ${ }^{\mathrm{TM}}$ mixing ceases. The final grout formulation is based on an iterative process of performing laboratory studies and numerical analyses. The laboratory studies were performed to optimize the grout viscosity, density, and thixotropic properties. The numerical studies were used to estimate the final components of the grout and wet sludge that will make up the monolith in tank TH-4. 
The best grout formulation was then used in laboratory leachability studies using a radioactive chemical surrogate in place of the actual tank sludge.

The grout properties investigated and the laboratory procedures used to establish a single grout for leachability testing are summarized in Sects. 4.3.1-4.3.3 for each of the three properties of concern: viscosity, density, and thixotropic behavior.

\subsubsection{Viscosity}

The main concern about the viscosity of the grout is the capability of high-pressure cement pumps (i.e., the Halliburton HT-400) to pump the grout. Laboratory equipment may not produce exactly the same mixture as an oil field colloidal mixer, but the laboratory blender can provide an economical first step in screening a candidate grout. The grout viscosity was measured using a Fann ${ }^{\mathrm{TM}}$ viscometer. Halliburton Oil Field Services indicated that their pumps could handle a grout with a maximum Fann ${ }^{\mathrm{TM}}$ viscometer reading of about $150 \mathrm{lb} / 100 \mathrm{ft}^{2}$ measured at $600 \mathrm{rpm}$ and with a 10-min gel strength of about $50 \mathrm{lb}_{\mathrm{f}} / 100 \mathrm{ft}^{2}$.

\subsubsection{Density}

The fresh grout should have an initial density of at least $1.5 \mathrm{~g} / \mathrm{mL}$ but less than about $1.75 \mathrm{~g} / \mathrm{mL}$. The lower limit is related to adding sufficient particles to the low-density sludges $(1.1 \mathrm{~g} / \mathrm{mL})$ so that a denser monolith is formed (at least $1.35 \mathrm{~g} / \mathrm{mL}$ ). The upper limit of $1.75 \mathrm{~g} / \mathrm{mL}$ is related to the pumpability of the grout and the fluidity for efficient mixing of the grout and sludge.

\subsubsection{Thixotropic/Sedimentation Control}

Although the 10-min gel strength measured with the Fann ${ }^{\mathrm{TM}}$ viscometer is an indication of the thixotropic strength gain of the grout with time, it does not provide detailed information about the grout's ability to suspend particles uniformly throughout the mixture of grout and sludge. Moreover, little information is available regarding the particle size distribution of the sludge. It is estimated that the average specific gravity of the sludge particles is around 4.5 , which is consistent with the types of radionuclides in the sludge, especially uranium and thorium. If the average particle size of the sludge were known, a Stokes Law type of analysis could be performed to select a physical surrogate with the same sedimentation characteristics as the tank sludge. Unfortunately, this information is not available, and it was not practical to obtain it with a high degree of certainty. Therefore, as a convenient physical surrogate, a quartz Ottawa calibration sand was selected as the physical sludge surrogate for use in the sedimentation studies. The Ottawa sand particle density of $2.75 \mathrm{~g} / \mathrm{cm}^{3}$ was a fine, uniform sand with $100 \%$ passing through the 30 -mesh size $(0.63 \mathrm{~mm})$ sieve and $100 \%$ being retained on the 100 -mesh size $(0.149 \mathrm{~mm})$ sieve.

The freshly made grout, slag and fly ash pretreatment (if needed), and sand-water surrogate were introduced into various containers [mostly 4-in.-diam polyvinyl chloride (PVC) pipe] and manually mixed by turning the PVC pipe end over end. After about 10 cycles of agitation, the PVC pipe was held upright and then clamped to a vertical stand. The assembly was allowed to stand overnight. The next day the PVC pipe was cut into various sections (usually 3 to 5 in. thick), and the unhardened grout was washed through a 200-mesh sieve. The slag-fly ash grout had not hardened after 24 hours and was easily washed through the 200-mesh sieve. This is an important feature for in-tank applications since the slow cure provides time to remix the sludge and grout to form a homogenous monolith. Furthermore, the slow cure does not generate much heat; this is radically different from cement grout, which may increase the waste temperature to more than $125^{\circ} \mathrm{F}$. All the fine sand retained on the 200 -mesh sieve was collected and placed in an oven to dry. This process was repeated for 3 to 7 sections of PVC pipe. This procedure allowed determination of the sand distribution over the height of the monolith formed by the grouted and sand-water surrogate. The incremental density of the monolith was also determined. These procedures allowed examination of the segregation of the sand from the grout. 


\subsection{PRELIMINARY GROUT TESTING RESULTS}

Fourteen different grout formulations were evaluated during the preliminary testing. The constituents for each grout formulation are presented in Table 7. Grout formulations 1 through 4 were used to develop laboratory testing techniques and refine the procedures for conducting the sand sedimentation tests. These four tests also allowed preliminary examination of the basic grout (Table 5, column 3) and the impact that bentonite had on the grout rheology. Results from the first four tests indicated that bentonite (or a gelling agent) was needed to keep the sand particles in suspension and that some portion of the bentonite had to be prehydrated to keep the sand uniformly suspended throughout the monolith. Tests 5 through 8 examined how different bentonite preparations (prehydration) influenced the grout's thixotropic behavior. Tests 9 and 10 used a proprietary grout additive (Rheomac ${ }^{\mathrm{TM}}$ UW 450) manufactured by Master Builders for water control. This additive was not able to keep the calibration sand in suspension. Furthermore, the GAAT Project Team wanted to use lower cost, "natural" products that are derived as by-products from a manufacturing process (e.g., fly ash and slag). Test 11 examined the influence of a very high ionic salt concentration on the bentonite (i.e., saltwater flocculation concerns about the bentonite). Finally, tests 12 and 13 examined using prehydrated bentonite slurry as mix water and adding slag and fly ash as a pretreatment. Test 14 examined the lowest possible amount of prehydrated bentonite that could be used (and still have uniformly distributed sand). Test 14 was essentially a lower-bound test, which may account for variations of mixing under field conditions.

\subsubsection{Results for Grout Tests 1 Through 4}

Grout test 1 used the basic grout used in the calculations discussed in Sect. 4.2. Even though a relatively rich grout was used (low water, dry blend ratio of 0.60), the sand-water surrogate instantly fell to the bottom of the mixer. Although the Fann ${ }^{\mathrm{TM}}$ viscometer reading of 111 at $600 \mathrm{rpm}$ and a 10 -min gel strength of 65 (Table 8) were within acceptable limits for pumping considerations, the grout did not have an adequate internal strength to keep any sand in suspension. Consequently, this grout was rejected.

The $14 \%$ dry bentonite added to grout 2 is considered excessive. The grout viscosity of $210 \mathrm{lb} / 100 \mathrm{ft}^{2}$ and gel strength of 61 would prevent this grout from being pumped through the high-pressure pumps. Therefore, grout 2 was rejected.

Prehydrating bentonite to form a slurry is a commonplace mixing procedure for introducing bentonite into a basic grout. Furthermore, prehydrated bentonite tends to retain its thixotropic behavior for a longer time when the bentonite is placed into a highly ionic solution. Therefore, grout test 3 was performed to estimate the maximum percentage of bentonite slurry that could be used as mixing water for combining the other grout constituents. When a slurry with about $8 \%$ bentonite was used as the mixing water, the grout formed a thick paste in the blender. Therefore, an $8 \%$ solution of prehydrated bentonite slurry does not produce an acceptable grout.

When the $d r y$ bentonite content was reduced to $4 \%$, the grout still did not posses any capabilities for suspending sand. Therefore, grout 4 was rejected.

\subsubsection{Results for Grout Tests 5 Through 8}

The first four tests revealed that the preliminary grout formulation with a dry bentonite could not be used as a means to keep any sand (sludge) in suspension. Some sort of prehydration of the bentonite (or other gelling agent) is required, with $8 \%$ representing an extreme upper bound. The decision was made to conduct a series of experiments using different types of prehydration and the dry addition of bentonite. Because $4 \%$ dry bentonite could not keep sand in suspension and $8 \%$ prehydrated bentonite produced an unpumpable grout, it was decided to conduct tests 5 through 8 using $6 \%$ bentonite. 
Table 7. Composition of dry blends, jetting slurries, and grouts tested in the scoping tests for an in situ GAAT grout using a sand-water surrogate to simulate the GAAT sludge

\begin{tabular}{|c|c|c|c|c|c|c|c|c|c|c|}
\hline \multirow{3}{*}{ Test } & \multicolumn{5}{|c|}{ Jetting slurry dry blend (wt \%) } & \multicolumn{2}{|c|}{$\begin{array}{l}\text { Jetting slurry } \\
\quad(\text { wt } \%)\end{array}$} & \multicolumn{3}{|c|}{ Monolith mixture (wt \%) } \\
\hline & \multirow{2}{*}{ Bentonite } & \multirow{2}{*}{ IRPC } & \multirow{2}{*}{ Fly ash } & \multirow{2}{*}{ Slag } & \multirow{2}{*}{ Cement } & \multirow{2}{*}{$\begin{array}{c}\text { Dry } \\
\text { blend }\end{array}$} & \multirow{2}{*}{ Water } & \multirow{2}{*}{ Jet slurry } & \multicolumn{2}{|c|}{ Surrogate } \\
\hline & & & & & & & & & Sand & Water \\
\hline 1 & 0 & 15 & 35 & 35 & 15 & 63 & 38 & 60 & $\mathrm{NA}^{a}$ & NA \\
\hline 2 & 14 & 8 & 30 & 36 & 12 & 63 & 38 & 60 & NA & NA \\
\hline 3 & $8^{b}$ & 8 & 30 & 36 & 18 & \multicolumn{5}{|c|}{$\begin{array}{l}\text { Became too thick, like putty, after adding only a small amount } \\
\text { of dry blend to the bentonite slurry. }\end{array}$} \\
\hline 4 & 4 & 11 & 30 & 36 & 19 & $54^{c}$ & 46 & 60 & 12 & 28 \\
\hline 5 & $6^{d}$ & 10 & 30 & 36 & 18 & 54 & 46 & 67 & 10 & 23 \\
\hline 6 & 6 & 10 & 30 & 36 & 18 & $54^{e}$ & 46 & 57 & 13 & 30 \\
\hline 7 & $6^{d}$ & 10 & 30 & 36 & 18 & $54^{e}$ & 46 & 57 & 13 & 30 \\
\hline \multirow[t]{2}{*}{8} & $6^{b}$ & 10 & 30 & 36 & 18 & $8^{f}$ & 92 & $18^{g} / 37^{h}$ & 14 & 32 \\
\hline & & & & & & $59^{i}$ & 41 & & & \\
\hline 9 & 0 & 14 & 30 & 36 & 20 & 59 & $41^{j}$ & 61 & 12 & 27 \\
\hline 10 & 0 & 14 & 30 & 36 & 20 & 59 & $41^{k}$ & 61 & 12 & 27 \\
\hline $11^{l}$ & 100 & & & & & 8 & 92 & 25 & 21 & $54^{m}$ \\
\hline 12 & $4.5^{b}$ & 10 & 32 & 36 & 17.5 & 51 & 49 & $52^{n} / 11^{o}$ & 12 & 25 \\
\hline 13 & $3^{b}$ & 10 & 34 & 36 & 17 & 50 & 50 & $52^{n} / 11^{o}$ & 12 & 25 \\
\hline 14 & $2.5^{b}$ & 10 & 34.5 & 36 & 17 & 50 & 50 & 57 & 14 & 29 \\
\hline
\end{tabular}

${ }^{a}$ Not applicable.

${ }^{b}$ The bentonite was prehydrated in the jetting water separate from the remainder of the dry blend.

${ }^{c}$ This jetting slurry was highly viscous, like ice cream; a pencil could stand up in it.

${ }^{d}$ Of the 6 wt $\%$ bentonite for the dry blend, 2 wt $\%$ was prehydrated and $4 \mathrm{wt} \%$ was in dry blend.

${ }^{e}$ Density of the jetting slurry was $1.51 \mathrm{~g} / \mathrm{mL}$.

${ }^{f}$ Weight percent of bentonite in the bentonite slurry only.

${ }^{g}$ Weight percent of the bentonite slurry in the final grout (added or jetted first).

${ }^{h}$ Weight percent of the dry blend slurry in the final grout (added or jetted after the bentonite slurry).

${ }^{i}$ Weight percent of the remainder of the dry blend in a slurry separate from the bentonite slurry.

${ }^{j}$ Exclusive of Master Builders Rheomac ${ }^{\mathrm{TM}}$ UW 450 tested in place of bentonite: $0.0075 \mathrm{~mL} / \mathrm{g}$ jetting water.

${ }^{k}$ Exclusive of Master Builders Rheomac ${ }^{\mathrm{TM}}$ UW 450 tested in place of bentonite: $0.0143 \mathrm{~mL} / \mathrm{g}$ jetting water.

${ }^{l}$ Salt flocculation test using bentonite slurry from Test 8.

${ }^{m}$ Salt water at a ratio of salt:water of 0.0612 and $0.0729 \mathrm{~g} / \mathrm{g}$ of $\mathrm{NaCl}$ and $\mathrm{NaNO}_{3}$, respectively.

${ }^{n}$ Weight percent of jetting slurry in final grout without the fly ash and slag dumped on the surrogate sludge before mixing.

${ }^{o}$ Weight percent of fly ash and slag (50:50 mix) in final grout dumped on surrogate sludge before mixing with jetting slurry. 
Table 8. Measured properties of the jetting slurry and grout for the scoping tests using a sand-water surrogate to simulate GAAT sludge

\begin{tabular}{ccccc}
\hline \multirow{2}{*}{ Test } & \multicolumn{2}{c}{ Jetting slurry rheology } & $\begin{array}{c}\text { Grout density } \\
(\mathrm{g} / \mathrm{mL})\end{array}$ & $\begin{array}{c}\text { Free water } \\
(\text { vol \%) }\end{array}$ \\
\cline { 2 - 3 } & $\begin{array}{c}\text { Fann }{ }^{\text {TM }} \text { reading at } \\
600 \mathrm{rpm}\end{array}$ & $\begin{array}{c}\text { 10-min. gel strength } \\
\left(\mathrm{lb}_{\mathrm{f}} / 100 \mathrm{ft}^{2}\right)\end{array}$ & 1.36 & 10.8 \\
2 & 111 & 65 & 1.26 & 2.4 \\
3 & 210 & 61 & Grout too thick一resembled a sticky putty & \\
4 & & 54 & $1.51^{a}$ & $5.6-8.0$ \\
5 & 101 & 58 & 1.36 & 1.9 \\
6 & 214 & 21 & 1.34 & 25.0 \\
7 & 76 & 21 & 1.39 & 8.9 \\
8 & 200 & $39^{b}$ & $1.17^{c}$ & 4.3 \\
9 & $118^{b}$ & $40^{d}$ & $1.31^{e}$ & 19.6 \\
10 & $50^{d}$ & 55 & $\sim 1.3$ & 16.2 \\
$11^{f}$ & 155 & 42 & $\sim 1.3$ & 0.5 \\
12 & 204 & 41 & 1.23 & 4.4 \\
13 & 111 & 28 & $1.38^{a}$ & 10.1 \\
14 & 139 & 28 & 1.33 & - \\
\hline
\end{tabular}

${ }^{a}$ Calculated, not measured.

${ }^{b}$ Bentonite slurry.

${ }^{c}$ Bentonite slurry mixed with surrogate sludge (bentonite-water-sand).

${ }^{d}$ Dry blend slurry without bentonite.

${ }^{e}$ Grout: dry blend slurry mixed with bentonite slurry-surrogate sludge mix.

${ }^{f}$ Bentonite slurry from test 8 without other dry blend additives in salt flocculation test.

Test 5 used $6 \%$ bentonite in which $4 \%$ was added dry to the grout and $2 \%$ was prehydrated using the grout mix water. This grout mixture produced a highly viscous grout with a Fann ${ }^{\mathrm{TM}}$ viscometer reading of 214 at $600 \mathrm{rpm}$ and a 10-min gel strength of 58 (Table 8). The 1020-mL test sample used for the sand sedimentation study (Table 9, test 5) had a fairly uniform distribution of sand, with sand concentrations varying between $0.134 \mathrm{~g} / \mathrm{mL}$ at the top of the monolith and $0.172 \mathrm{~g} / \mathrm{mL}$ at the bottom. This grout was rejected because the viscosity was too high.

The procedure used to wet-sieve the sand was problematic in test 5 . The sand retrieved by wetsieving was about $20 \%$ less than that added to the original sample. It was decided to use a single large vessel for adding the grout and sand-water surrogate. A 3-ft-long PVC pipe with a 4-in. diameter was most convenient. Also, the PVC pipe was easily cut into discrete sections, which allowed better resolution of the sand distribution.

Grout test 6 was started with a grout containing only dry bentonite (6\% used for test 6 in Table 7). The wet-sand sieving procedure had been perfected, and it was interesting to examine how poorly the sand was distributed over a large sample. (Test 6 was the first test performed using a 4-in.-diam PVC pipe as a mixing vessel.) The total volume of grout plus sand-water surrogate produced an initial wet 
Table 9. Sand distribution in a column of grout from the scoping test grouts

\begin{tabular}{|c|c|c|c|c|c|c|c|c|c|c|}
\hline \multirow{2}{*}{ Test } & & \multicolumn{9}{|c|}{ Column section from PVC pipe } \\
\hline & & 1 (Top) & 2 & 3 & 4 & 5 & 6 & 7 & 8 & 9 \\
\hline \multirow[t]{3}{*}{5} & $\mathrm{~mL}^{a}$ & 220 & 200 & 200 & 200 & 200 & & & & \\
\hline & $\mathrm{g} / \mathrm{mL}^{b}$ & - & - & - & - & - & & & & \\
\hline & Conc.$^{c}$ & 0.134 & 0.118 & 0.126 & 0.110 & 0.172 & & & & \\
\hline \multirow[t]{3}{*}{6} & $\mathrm{~mL}^{a}$ & 573 & 600 & 621 & 666 & & & & & \\
\hline & $\mathrm{g} / \mathrm{mL}^{b}$ & 1.31 & 1.45 & 1.59 & 1.75 & & & & & \\
\hline & Conc. $^{c}$ & 0.004 & 0.085 & 0.301 & 0.606 & & & & & \\
\hline \multirow[t]{3}{*}{7} & $\mathrm{~mL}^{a}$ & 607 & 596 & 640 & 580 & 525 & & & & \\
\hline & $\mathrm{g} / \mathrm{mL}^{b}$ & 1.39 & 1.43 & 1.57 & 1.45 & 1.46 & & & & \\
\hline & Conc. $^{c}$ & 0.167 & 0.198 & 0.206 & 0.216 & 0.223 & & & & \\
\hline \multirow[t]{3}{*}{8} & $\mathrm{~mL}^{a}$ & 654 & 606 & 626 & 660 & 614 & 609 & 614 & 606 & 528 \\
\hline & $\mathrm{g} / \mathrm{mL}^{b}$ & 1.25 & 1.31 & 1.28 & 1.27 & 1.31 & 1.34 & 1.32 & 1.35 & 1.31 \\
\hline & Conc. $^{c}$ & 0.174 & 0.189 & 0.183 & 0.190 & 0.196 & 0.204 & 0.196 & 0.204 & 0.204 \\
\hline \multirow[t]{3}{*}{9} & $\mathrm{~mL}^{a}$ & 1535 & 1535 & & & & & & & \\
\hline & $\mathrm{g} / \mathrm{mL}^{b}$ & 1.24 & 1.50 & & & & & & & \\
\hline & Conc. $^{c}$ & 0.027 & 0.279 & & & & & & & \\
\hline \multirow[t]{3}{*}{10} & $\mathrm{~mL}^{a}$ & 1467 & - & 1013 & & & & & & \\
\hline & $\mathrm{g} / \mathrm{mL}^{b}$ & - & - & - & & & & & & \\
\hline & Conc. $^{c}$ & 0.032 & - & 0.474 & & & & & & \\
\hline \multirow[t]{3}{*}{$11^{d}$} & $\mathrm{~mL}^{a}$ & $345^{e}$ & 300 & 400 & & & & & & \\
\hline & $\mathrm{g} / \mathrm{mL}^{b}$ & - & - & - & & & & & & \\
\hline & Conc. $^{c}$ & 0.250 & 0.230 & 0.269 & & & & & & \\
\hline \multirow[t]{3}{*}{12} & $\mathrm{~mL}^{a, f}$ & 700 & 660 & 670 & 680 & 690 & 660 & 510 & & \\
\hline & $\mathrm{g} / \mathrm{mL}^{b}$ & - & - & - & - & - & - & - & & \\
\hline & Conc. $^{c}$ & 0.153 & 0.147 & 0.158 & 0.164 & 0.160 & 0.165 & 0.180 & & \\
\hline \multirow[t]{3}{*}{13} & $\mathrm{~mL}^{a}$ & 550 & 530 & & & & & & & \\
\hline & $\mathrm{g} / \mathrm{mL}^{b}$ & 1.45 & - & & & & & & & \\
\hline & Conc. $^{c}$ & 0.167 & 0.190 & & & & & & & \\
\hline \multirow[t]{3}{*}{14} & $\mathrm{~mL}^{a}$ & 550 & 450 & & & & & & & \\
\hline & $\mathrm{g} / \mathrm{mL}^{b}$ & 1.41 & - & & & & & & & \\
\hline & Conc. $^{c}$ & 0.211 & 0.240 & & & & & & & \\
\hline
\end{tabular}

${ }^{a}$ Grout volume of column section in milliliters.

${ }^{b}$ Measured monolith density for column section in grams/milliliter.

${ }^{c}$ Sand concentration in monolith for column section in grams of sand/milliliter monolith.

${ }^{d}$ Bentonite slurry from test 8 without other dry blend additives in salt flocculation test.

${ }^{e}$ Produced an oatmeal-looking top; hence, salt did cause some bentonite flocculation, but bentonite still suspended and distributed sand well from comparison of sand concentrations from top to bottom.

${ }^{f}$ Grout volume calculated from measured section grout masses assuming density of $1.38 \mathrm{~g} / \mathrm{mL}$. 
volume of $3387 \mathrm{~mL}$, as indicated on the upper right-hand side of Fig. 4. The numerical calculations for weight-volume had an estimated value of $3349 \mathrm{~mL}$, a difference of about $1 \%$. Therefore, it appears that the numerical weight-volume calculations provide reasonable estimates for the actual measured values. After settling overnight, about $850 \mathrm{~mL}$ of bleed water was sitting atop the consolidated monolith. This represents a bleed water content of about $25 \%$, which is considered excessive for $6 \%$ bentonite. Furthermore, as shown in Fig. 4, the sand concentration varied widely, with a small amount of sand in the top of the monolith $(<0.1 \mathrm{~g} / \mathrm{mL})$ and most of the sand in the bottom of the PVC tube $(0.6 \mathrm{~g} / \mathrm{mL})$. The monolith's unit weight was also poorly distributed and varied from about $1.2 \mathrm{~g} / \mathrm{mL}$ at the top to $1.8 \mathrm{~g} / \mathrm{mL}$ at the bottom. Clearly, the $6 \%$ dry bentonite was not effective in controlling sedimentation.

Test 7 used $6 \%$ bentonite, with one-third of the bentonite being prehydrated with the grout mix water. The Fann ${ }^{\mathrm{TM}}$ viscometer data measured for this grout are shown in Fig. 5. The 600-rpm value of 200 makes this grout marginal for high-pressure pumping. Halliburton Oil Field Services indicated that this grout had a potential for being pumped but wanted to test it in a full-scale demonstration using highspeed colloidal mixers. A total of $3258 \mathrm{~mL}$ of grout and sand-water surrogate was used for the sedimentation studies. Results from the wet-sand sieving and density measurements are summarized in Table 9 and plotted in Fig. 6. The $290 \mathrm{~mL}$ of measured bleed water represents a water loss of about 9\%, which is an acceptable amount of free water. There were 594 grams of sand introduced into the test, which would correspond to a uniformly distributed sand concentration of $0.20 \mathrm{~g} / \mathrm{mL}(594 \mathrm{~g} / 2968 \mathrm{~mL}-$ monolith total volume after the bleed water was extracted). The sand concentration plotted in Fig. 6 shows a uniformly distributed sand concentration of about $0.20 \mathrm{~g} / \mathrm{mL}$. The monolith density of $1.4 \mathrm{~g} / \mathrm{mL}$ is relatively constant over the entire thickness of the monolith (an approximately 15-in.-thick monolith formed in PVC pipe). The fractional constituents of wet sludge, water, and grout (cement, slag, fly ash, illite, and bentonite) in the consolidated monolith (test 7) are shown in Fig. 7. In general, it appears that about $65 \%$ of the monolith consists of wet sludge and water. This monolith may have insufficient particles to create a low-conductivity monolith with low leachability characteristics. Therefore, grout 7 should be considered as a second choice to the preferred grout formulation, which ultimately was grout formulation 13.

Grout test 8 used a two-stage injection strategy. First, an $8 \%$ solution of prehydrated bentonite was injected as a pretreatment to cut the sludge and place it into suspension. Then the slag-fly ash grout was injected (Table 7, test 8 ). Although the grout rheology measured using the Fann ${ }^{\mathrm{TM}}$ viscometer produced a pumpable bentonite slurry and slag-fly ash grout (Fig. 8) and the sand surrogate distribution and unit weight were uniformly distributed with only $250 \mathrm{~mL}$ of water bleed (Fig. 9), the monolith contained about $75 \%$ wet sludge and water (Fig. 10). Therefore, it is thought that this formulation would leave too little solid material in the final monolith to create a low-conductivity, diffusion-resistant monolith.

\subsubsection{Results for Grout Tests 9 and 10}

Tests 5 through 8 indicated that using $6 \%$ bentonite could produce a marginally pumpable grout (grout 7 needs to be checked using full-scale oil field colloidal mixers) with excellent control over the sand surrogate segregation. However, it was thought that the final constituents in the monolith might not produce an acceptable (diffusion-resistant) waste form. Hence, two additional injection strategies were examined during the remaining laboratory tests. The first was to try special chemical additives for controlling the rheology of the grout. The second was to mechanically stow dry slag and fly ash onto the top of the sludge before performing the MPI ${ }^{\mathrm{TM}}$ process. The turbulent mixing caused by the MPI ${ }^{\mathrm{TM}}$ process would ensure that the pretreatment would be homogeneously incorporated into the monolith. [There was evidence of this when solidifying buried waste with a sand cover; essentially the top 12 in. of sand were uniformly incorporated into the monolith (Fig. 1)].

Tests 9 and 10 (Table 7) used a proprietary grout additive, Rheomac ${ }^{\mathrm{TM}} \mathrm{UW} 450$, manufactured by Master Builders. The Fann ${ }^{\mathrm{TM}}$ viscometer data for this grout produced a marginally pumpable grout (Table 8) and did not produce a uniformly distributed sand concentration (Table 9). Therefore, this chemical additive was rejected. 
ORNL DWG 97C-86R

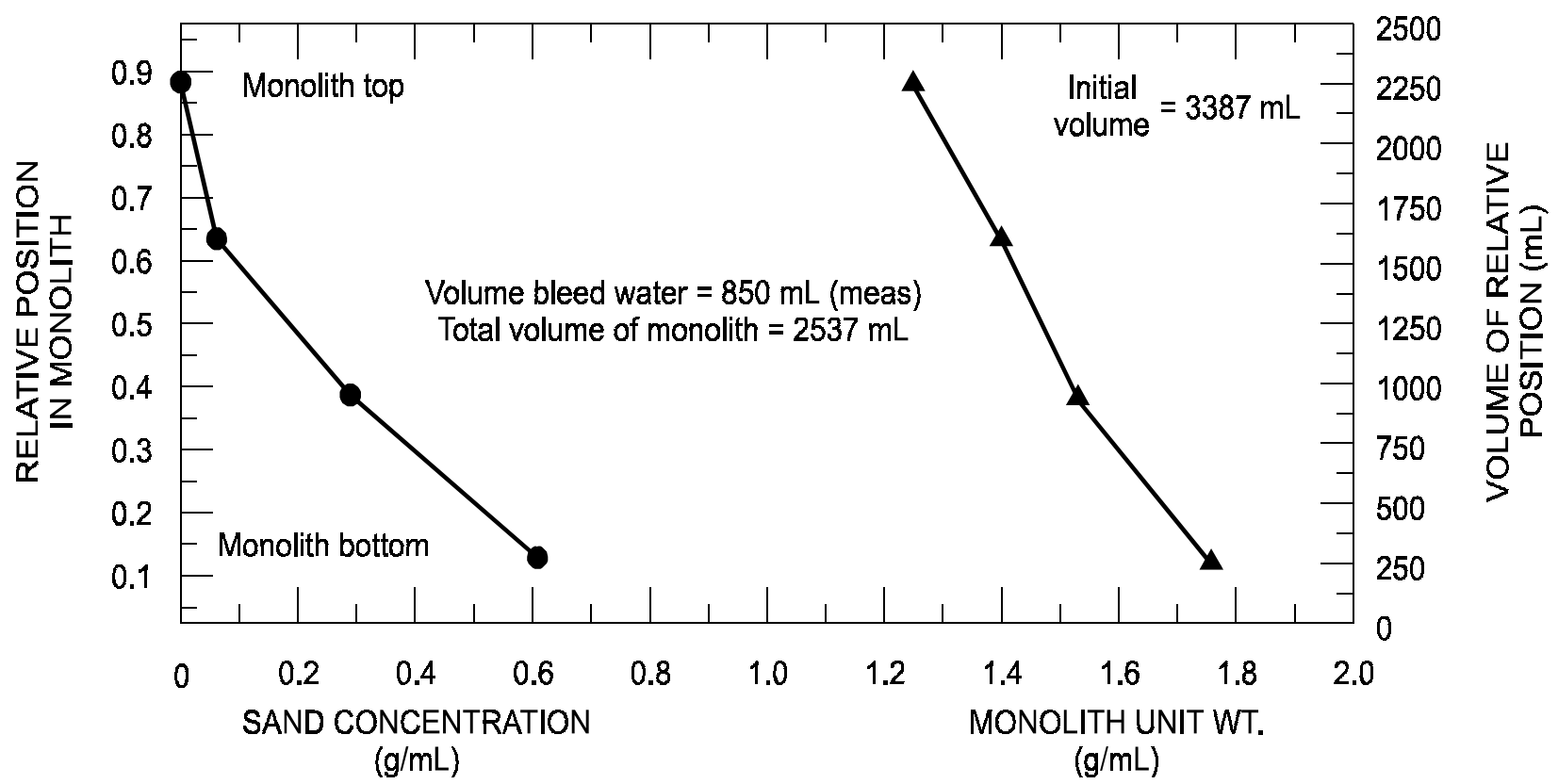

Fig. 4. Summary of sedimentation study performed for GAAT grout: grout test $6-6 \%$ bentonite, no prehydration.

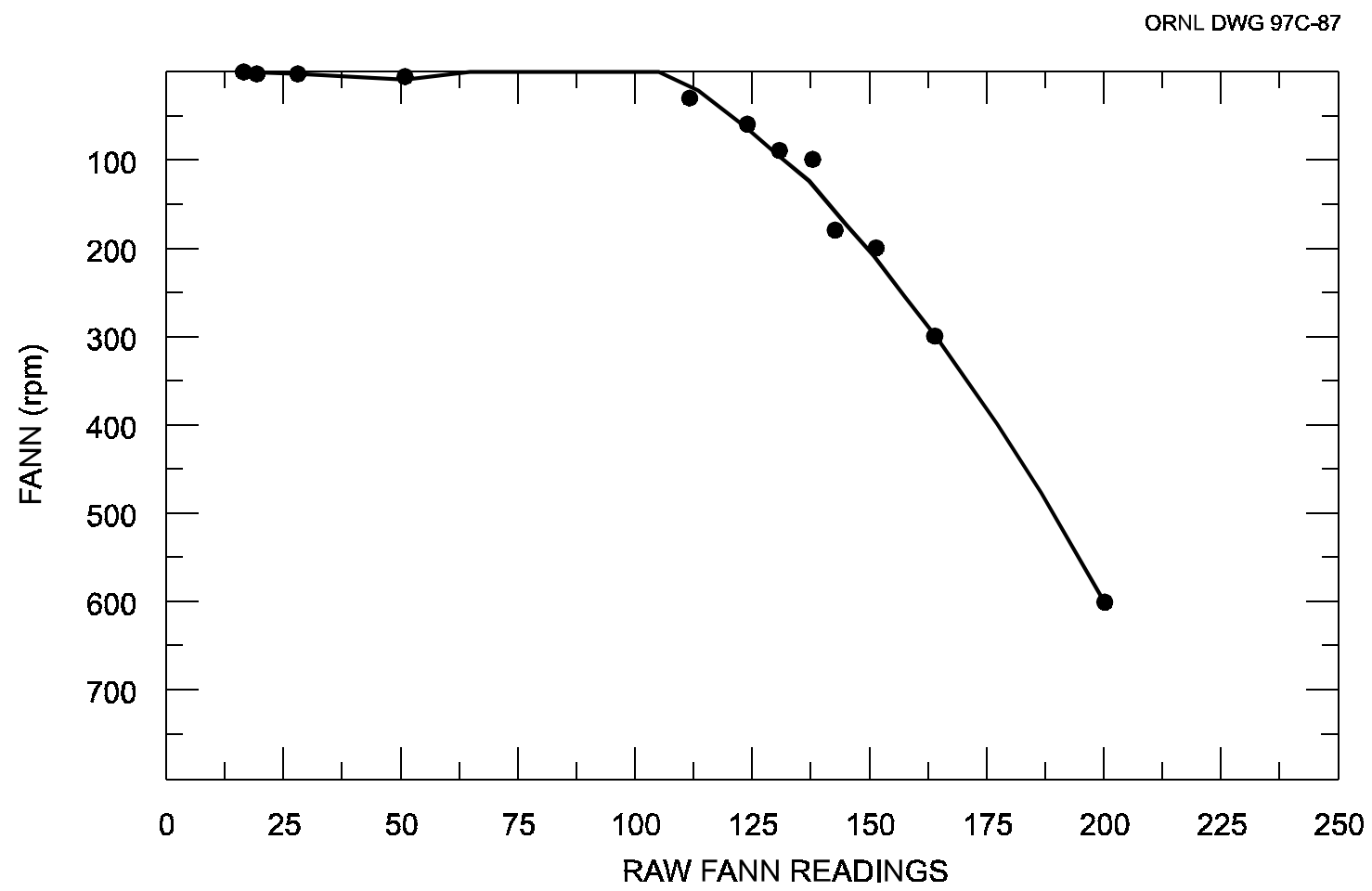

Fig. 5. Compilation of Fann ${ }^{\mathrm{TM}}$ viscometer readings for GAAT grout: grout test $7-6 \%$ bentonite, $1 / 3$ prehydrated. 
ORNL DWG 97C-88R

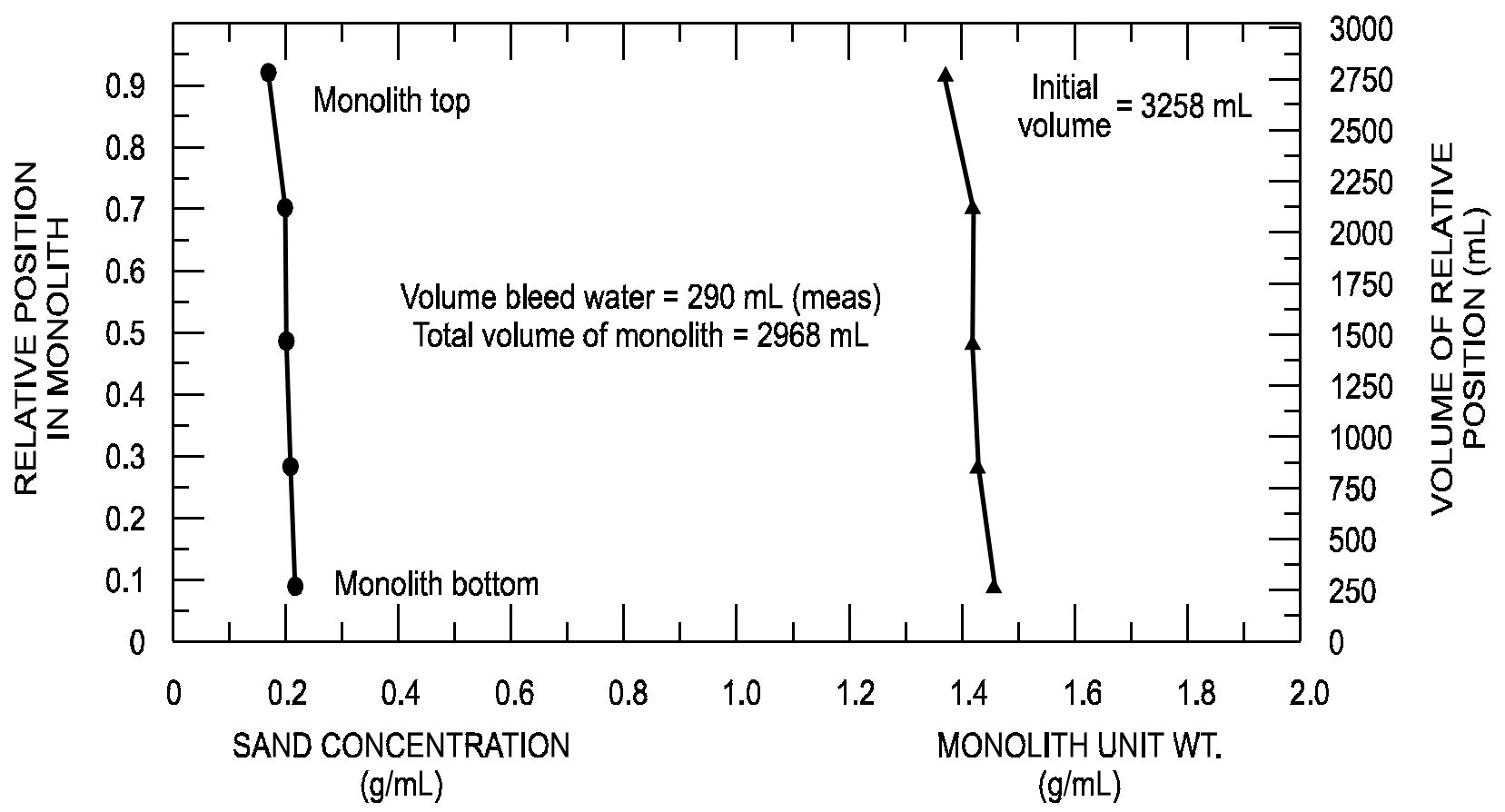

Fig. 6. Summary of sedimentation study performed for GAAT grout: grout test $7-6 \%$ bentonite, $1 / 3$ prehydrated.

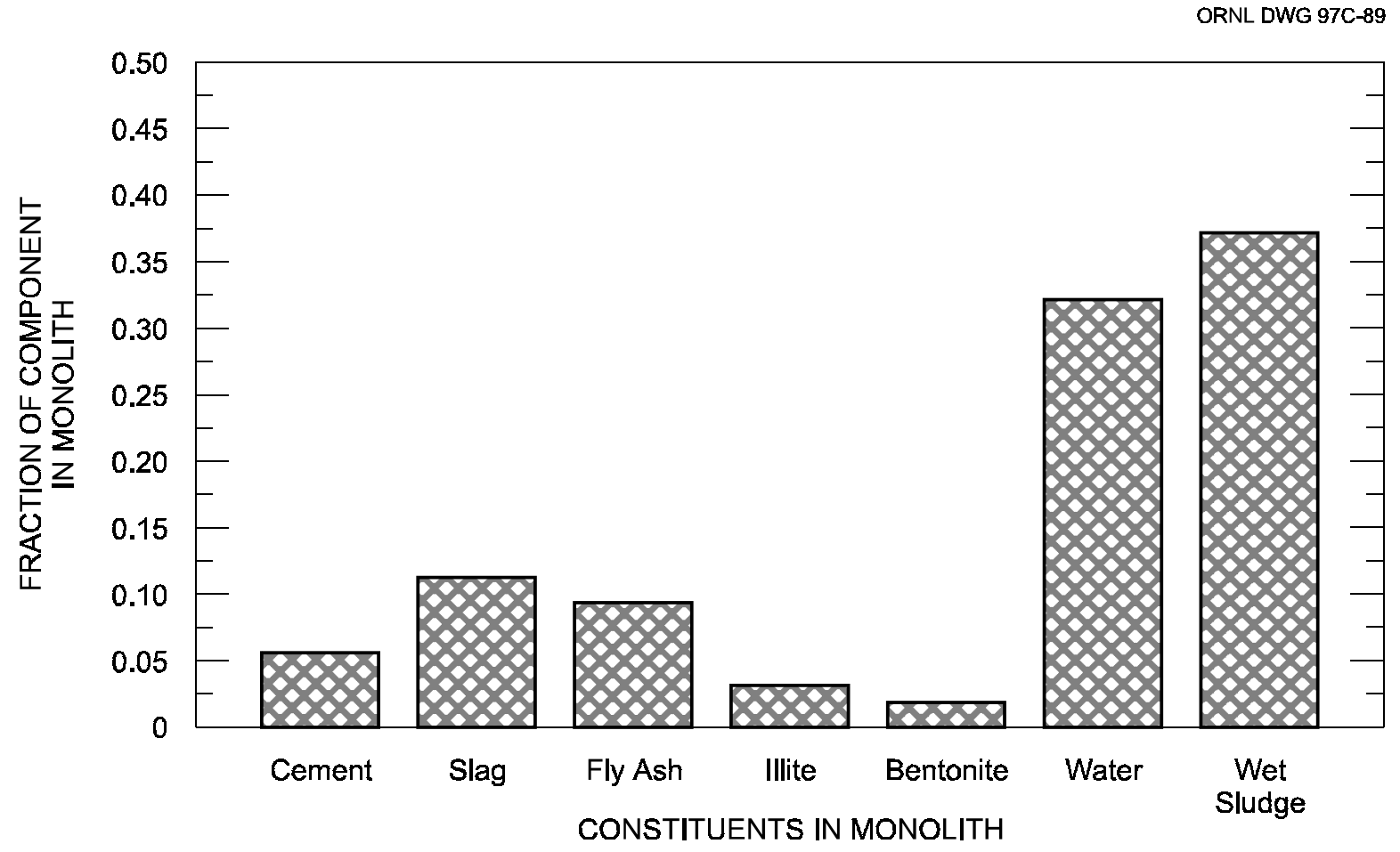

Fig. 7. Fraction of constituents in monolith, GAAT grout: grout test $7-6 \%$ bentonite, $1 / 3$ prehydrated with jetting water. 


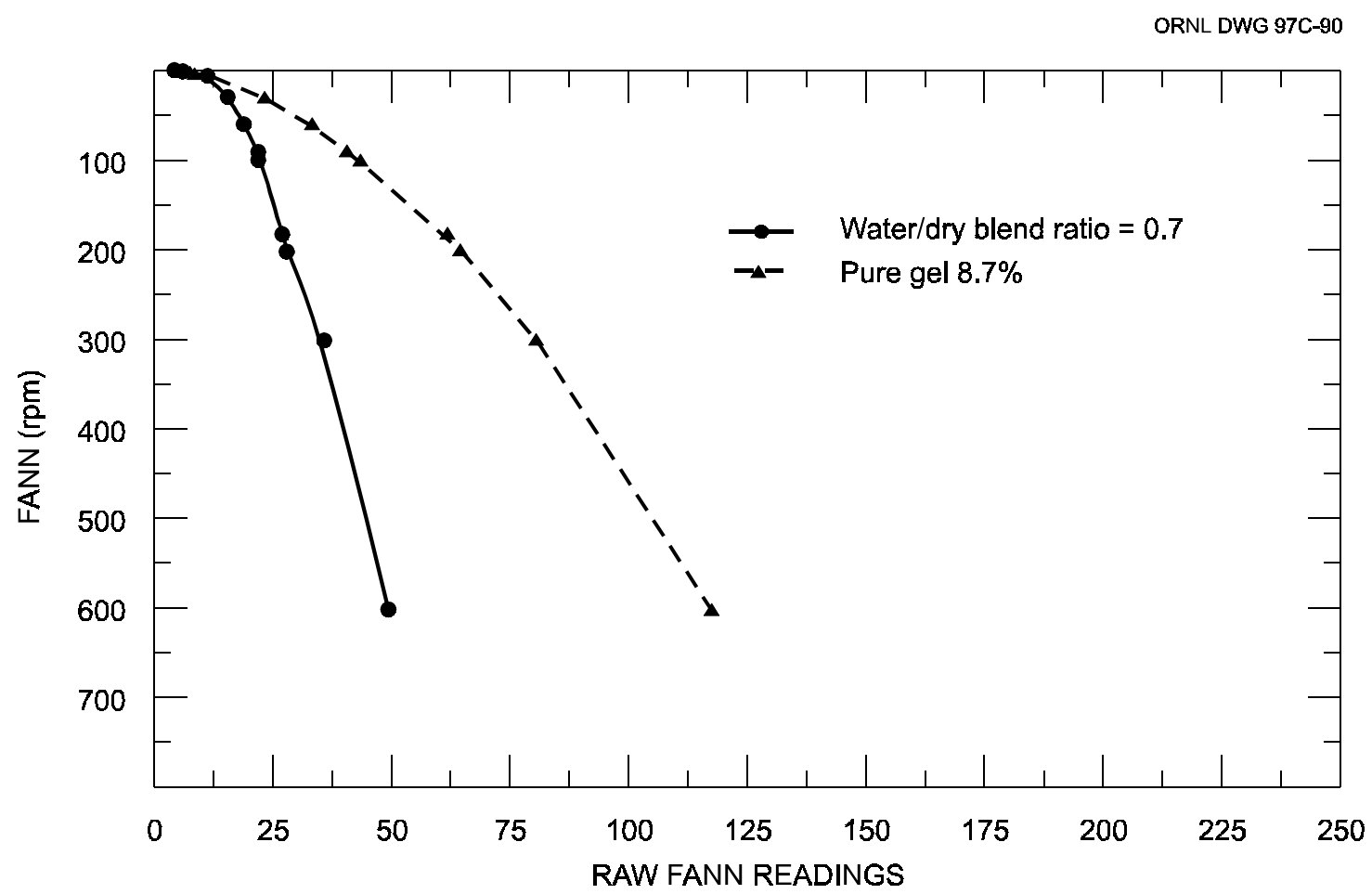

Fig. 8. Compilation of Fann ${ }^{\mathrm{TM}}$ viscometer readings for GAAT grout: grout test 8-pure gel $8.7 \%+$ dry blend.

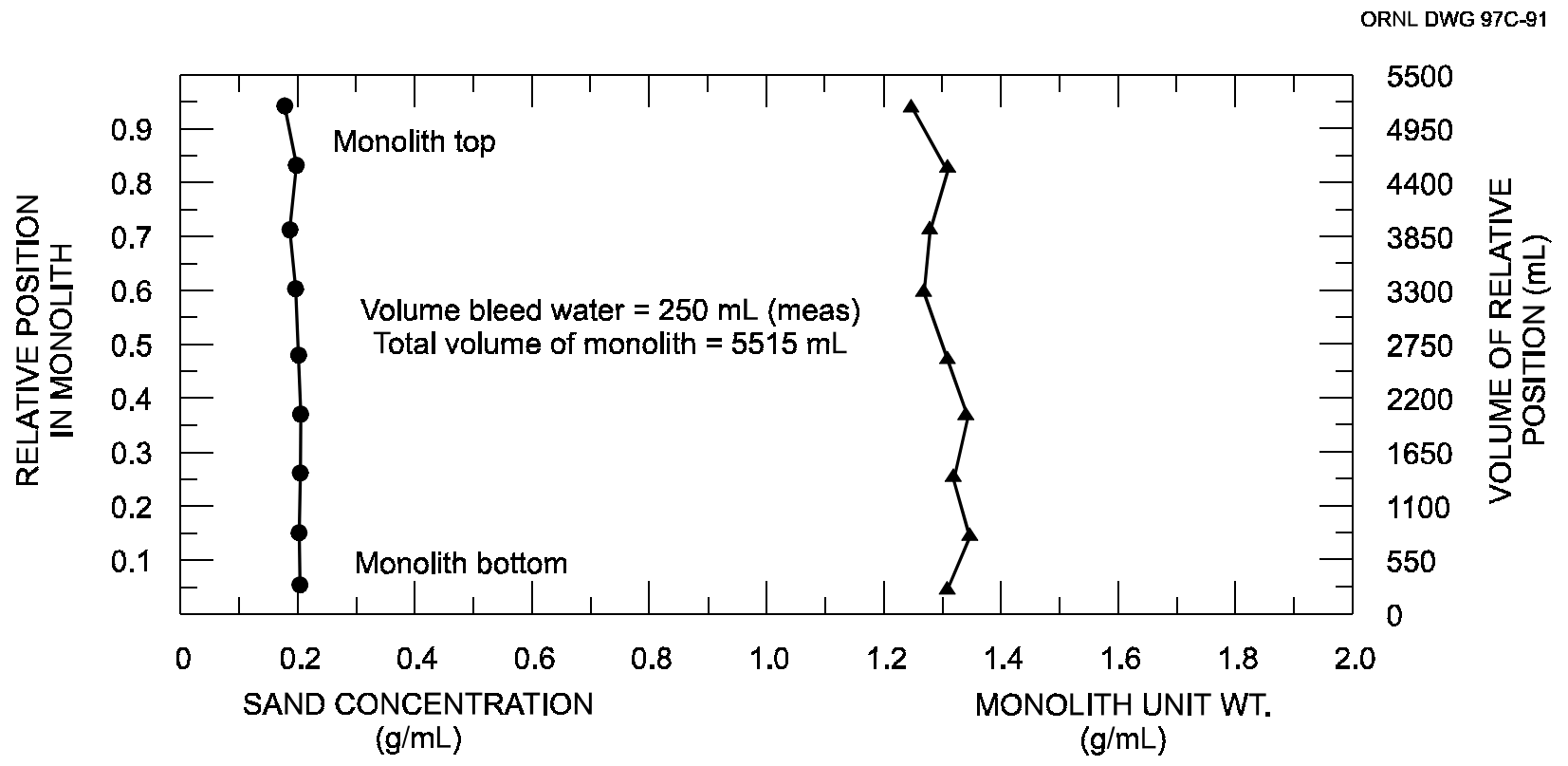

Fig. 9. Summary of sedimentation study performed for GAAT grout: grout test 8 -pure gel $8.7 \%+$ dry blend. 


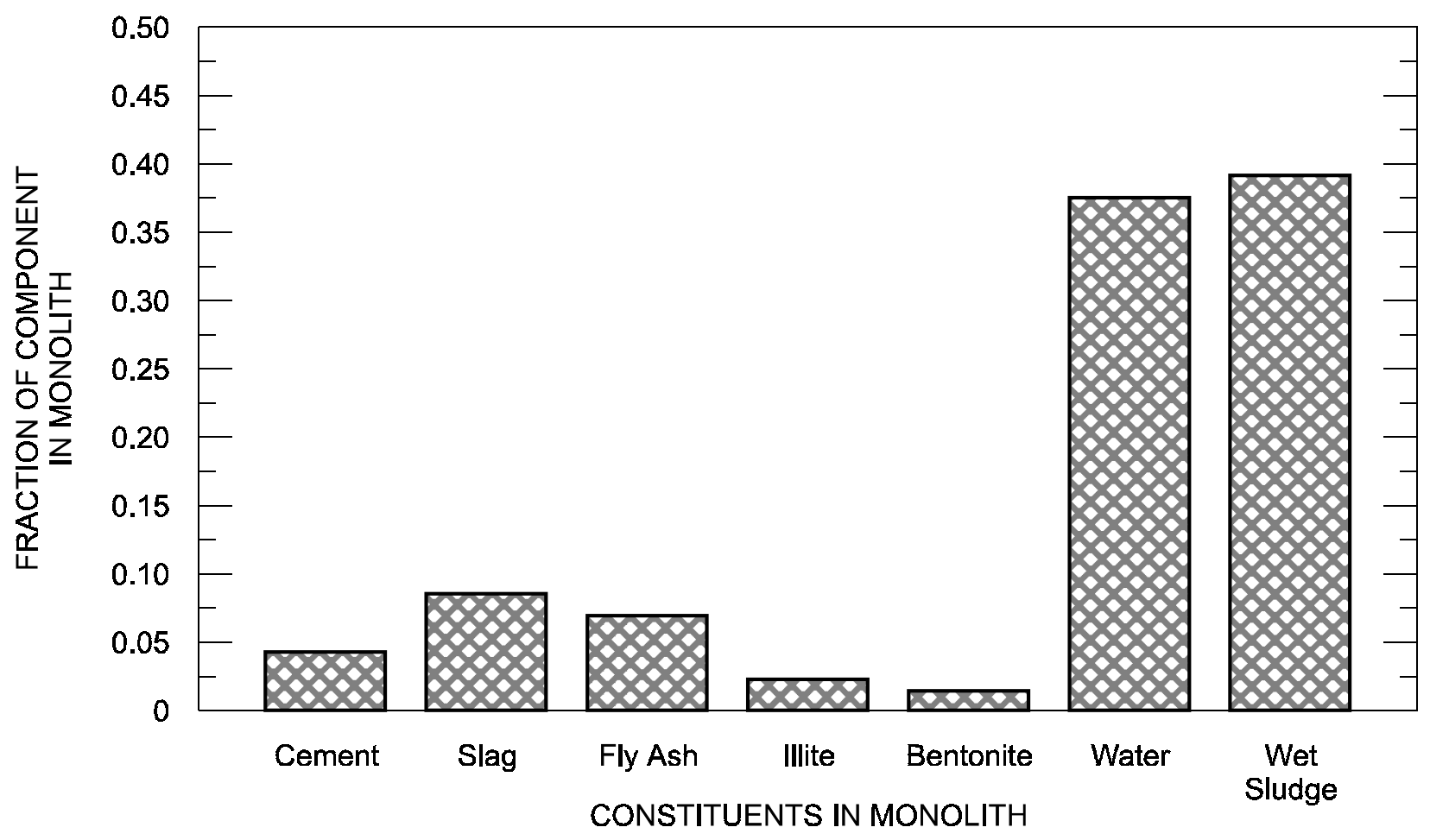

Fig. 10. Fraction of constituents in monolith, GAAT grout: grout test 8 -pure gel $8.7 \%+$ dry blend.

\subsubsection{Results for Grout Test 11: Salt Flocculation Test}

It was unclear at this juncture in the test program if a search for another chemical additive was warranted to obtain the desired grout properties. Conversely, additional studies could be conducted using a lower concentration of bentonite. It was decided to recommend using bentonite because this was thought to be a more acceptable material for injection when compared with proprietary chemical additives. However, before starting additional bentonite slurry tests, it was necessary to ensure that the bentonite would not experience severe lose of thixotropic strength caused by an adverse reaction with a highly ionic chemical surrogate. The chemical surrogate planned for the leaching tests was considered a highly ionic solution, the chemical composition of which might cause saltwater flocculation problems with the bentonite. Therefore, test 11 was performed to examine how hydrated bentonite behaves in a highly ionic solution.

Test 11 was conducted with an $8.9 \%$ solution of bentonite slurry. This freshwater slurry was combined with a sand-water surrogate, in which the water surrogate had an $11 \%$ solids content of salt (sodium chloride and sodium nitrate). The results from the small-scale sample $(1051 \mathrm{~mL})$ indicated that little bleed water was generated $(5 \mathrm{~mL}$, as shown in Fig. 11) after about 8 hours of contact between the bentonite and the highly ionic solution. It is thought that if the bentonite can remain thixotropic for about 6 to 8 hours, any suspended sludge will not settle to the tank bottom as the fluid monolith consolidates to a stable form. The sand surrogate used in the salt flocculation tests was uniformly distributed over the column height, with all sand concentration data plotted in Fig. 11 being about $0.2 \mathrm{~g} / \mathrm{mL}$ (which is the concentration for a uniformly distributed sand used for these tests). If the bentonite representing $6 \%$ of a dry blend is prehydrated in the jetting slurry, an $8.7 \%$ bentonite slurry is created (see test 8 in Table 7). Test 11 showed that this prehydrated $8.7 \%$ bentonite slurry is not adversely affected by a highly ionic salt solution and can maintain its sand-suspending properties well. 
ORNL DWG 97C-93

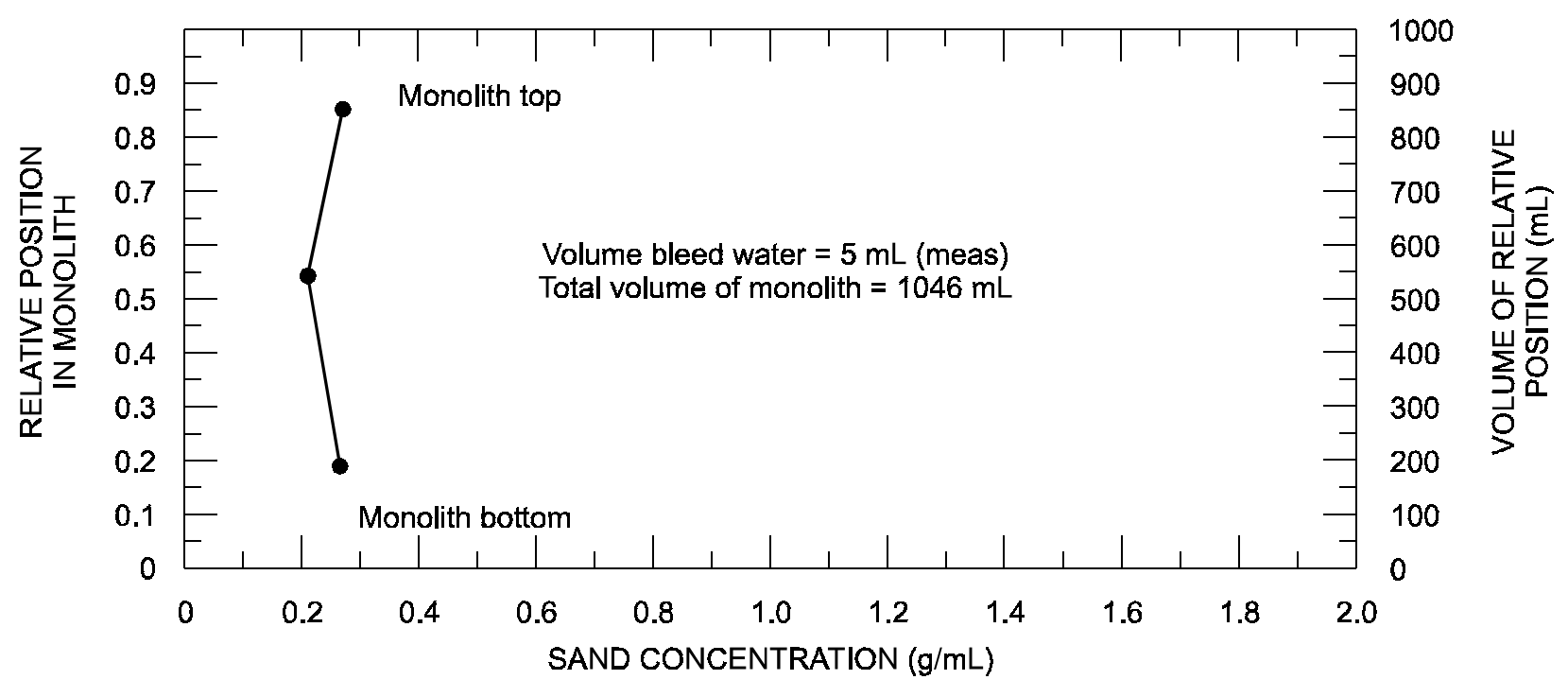

Fig. 11. Summary of sedimentation study performed for GAAT grout: grout test 11-pure gel $8.7 \%+$ $11 \%$ salt.

\subsubsection{Results for Grout Tests 12 Through 14}

Results from tests 1 through 11 indicated that a bentonite content as high as $6 \%$ in the dry blend requires a double injection with a separate injection of the bentonite, with the exception of grout formulation 7, which is still considered as a candidate. The final testing phase focused on grouts with a 3 to $4.5 \%$ prehydrated bentonite slurry. Furthermore, to increase the density of the monolith and the number of grout particles (especially fly ash and slag), it was decided to mimic the mechanical stowing of dry fly ash and slag in the laboratory (see Sect. 4.2).

Results from test 12 , in which $4.5 \%$ bentonite was prehydrated, produced a pumpable grout (Fann ${ }^{\mathrm{TM}}$ viscometer reading of 139 at $600 \mathrm{rpm}$ - see Table 8 ) and a uniformly distributed sand concentration that varied from $0.153 \mathrm{~g} / \mathrm{mL}$ of sand at the top to $0.180 \mathrm{~g} / \mathrm{mL}$ of sand at the bottom of the PVC pipe (Table 9). The total monolith size was about $4570 \mathrm{~mL}$. Hence, grout 12 was acceptable for injection.

At this stage in the research the supplies of slag and fly ash were starting to run low. Therefore, the last two tests (13 and 14) were conducted on relatively small samples, typically $1000 \mathrm{~mL}$. Furthermore, the formulations for grouts 12,13 , and 14 are essentially the same with a slight difference in the percentage of bentonite. These formulas were chosen to examine how the sand-suspension characteristics of the grout changes with minor changes in the percentage of bentonite (i.e., the possible range of variation in the field).

Grout 13, with $3 \%$ bentonite, produced a pumpable mix with good sand-suspension characteristics. Sand concentrations were $0.167 \mathrm{~g} / \mathrm{mL}$ in the upper $500 \mathrm{~mL}$ of the $1000-\mathrm{mL}$ cylinder and $0.190 \mathrm{~g} / \mathrm{mL}$ in the lower portion. Therefore, grout 13 was acceptable for injection.

Grout 14 also had acceptable Fann ${ }^{\mathrm{TM}}$ viscometer readings (80) and good sand-suspension qualities. Grout 14 should be considered as a lower bound for the percentage of prehydrated bentonite $(2.5 \%)$. 


\subsection{GROUT/MONOLITH FORMULA FOR LEACHABILITY TESTING}

These preliminary scope tests produced several grouts that are acceptable for injection, especially grouts 12 and 13 and possibly grout 7 . The numerical calculations used to estimate the monolith composition were based on using grout 13 and the strategy of mechanically stowing equal amounts of slag and fly ash as a pretreatment onto the sludge in tank TH-4. The calculations resulted in a monolith with a composition of about $35 \%$ wet sludge, $28 \%$ water, and $37 \%$ grout solids (Fig. 12; individual percentages for each component of the monolith are listed in Table 10). Note that grout 7 produced grout/sludge constituents similar to grout 13 (compare Fig. 7 to Fig. 12). Therefore, the makeup of the grouted monolith is similar using jetting only vs jetting plus pretreatment with slag and fly ash. However, since budgets were tight for testing of the grout-radioactive surrogate (Table 2), it was decided to test grout 13, which had about 5\% more solids (and therefore should have better leach and diffusion resistance) than grout 7. However, if the MPITM system is considered for in-tank solidification, grout 7 should be reexamined since this MPI ${ }^{\mathrm{TM}}$ strategy only relies on jetting and no pretreatment.

ORNL DWG 97C-94

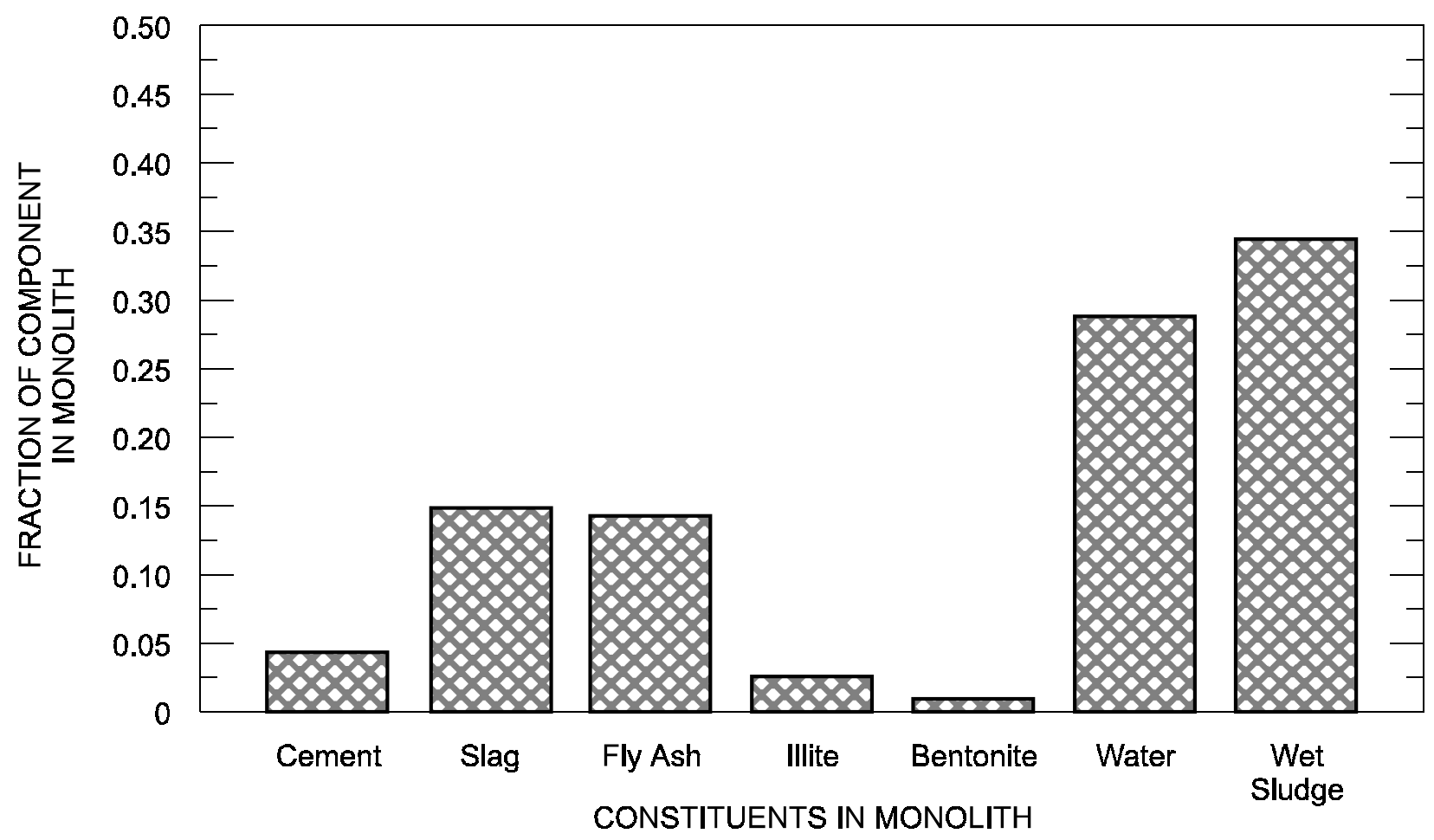

Fig. 12. Fraction of constituents in monolith, GAAT tank TH-4, grout 13. 
Table 10. Composition of the in situ monolith for GAAT sludges selected for sensitivity testing: Table 7, grout 13

Composition in the final

Component monolithic structure of solidified waste (wt \%)

\begin{tabular}{llr}
\hline Jetting slurry & IRPC & 2.6 \\
& Bentonite $^{a}$ & 0.8 \\
& Fly ash & 8.8 \\
& Slag & 9.3 \\
& Cement & 4.4 \\
& Injection water & 25.8 \\
Preadded additives $^{b}$ & Fly ash & 5.5 \\
\multirow{2}{*}{ Surrogate tank contents } & Slag & 5.5 \\
& Wet sludge & 34.5 \\
Total & Supernate water & 2.9 \\
& & $\mathbf{1 0 0 . 0}$ \\
\hline
\end{tabular}

${ }^{a}$ Prehydrated in mixing water before mixing with other dry blend components.

${ }^{b}$ Stabilizing additives mechanically stowed onto surrogate tank contents before grout mixing. 


\section{SENSITIVITY TESTING}

\subsection{SAMPLE PREPARATION}

\subsubsection{Surrogate Preparation}

The surrogate GAAT wet sludge used for sensitivity testing was prepared from reagent grade chemicals according to the composition listed in Table 1 . The chemicals were allowed to hydrolyze at least overnight by mixing with the recipe water specified in Table 11.

\subsubsection{Blending}

The dry blends that were mixed with the surrogate wet sludge to make grouts consisted of blends of two or more of the following dry powders: (1) ground granulated blast furnace slag (slag) with a Blaine fineness of $6220 \mathrm{~cm}^{2} / \mathrm{g}$ from the Koch Minerals Co., (2) Type I-II Portland cement (cement) from the Dixie Cement Co., (3) Class F fly ash (fly ash) from the American Fly Ash Co., (4) IRPC from the American Art Clay Co., and (5) bentonite clay (bentonite) from the Benton Clay Co. The dry blends were blended for 2 hours in an 8-qt twin-shell blender (or V-blender) from the Patterson-Kelley Co.

\subsubsection{Mixing}

The sensitivity test grouts were mixed in an Osterizer ${ }^{\mathrm{TM}} 14$-speed blender to simulate the shearing action of clay mixers and the turbulence created by the high-speed jets $(775 \mathrm{ft} / \mathrm{s})$ used to inject the grouts into the sludge. The mixing was done in two steps: (1) a slurry mix of water and dry blend was mixed (jetting slurry), and (2) the jetting slurry was mixed with the surrogate sludge, and any additive ingredients were added to the sludge but not mixed in (and not projected to be jetted into the tank). The blender speed and mixing time were varied to achieve a well-mixed slurry or grout, usually at high-speed for a few minutes. It is estimated that about 20 minutes of jetting would be required for the tank TH- 4 solidification campaign. The bentonite was prehydrated, usually by soaking it in water for 1 to 2 hours before mixing the jetting slurry. The procedure for generating leach samples spiked with radionuclides consisted of spiking the surrogate GAAT sludge with the radionuclides, mixing it in the blender for a few minutes, allowing equilibration for $20 \mathrm{~min}$, mixing it with the dry blend and jetting water into the grout, casting grout leach cylinders in the Teflon ${ }^{\mathrm{TM}}$ mold sealed at the bottom with silicone caulk, and curing for 28 days in the humidity cabinet at $30 \pm 1^{\circ} \mathrm{C}$.

\subsubsection{Curing}

The freshly made grout was cured at $30 \pm 1^{\circ} \mathrm{C}$ in a humidity cabinet or at room temperature in a sealed container. The samples were cured the standard 28 days for the sensitivity testing.

\subsection{PERFORMANCE TESTING OF SOLIDIFIED RADIOACTIVE SURROGATE}

The sensitivity testing consisted of measuring the density, 28-day unconfined compressive strength, 28-day free water, 28-day TCLP performance, and the 28-day leachability index of ${ }^{85} \mathrm{Sr}$ and ${ }^{137} \mathrm{Cs}$. 
Table 11. Composition of GAAT surrogate sludges for sensitivity testing

\begin{tabular}{|c|c|c|c|}
\hline \multirow{2}{*}{ Compound } & \multicolumn{3}{|c|}{ Concentration $(\mathrm{wt} \%)^{a}$} \\
\hline & Standard surrogate & Maximum water & Minimum water \\
\hline $\mathrm{HgCl}_{2}$ & 0.028 & 0.014 & 0.043 \\
\hline $\mathrm{PbO}$ & 0.346 & 0.173 & 0.535 \\
\hline $\mathrm{Al}(\mathrm{OH})_{3}$ & 3.303 & 1.654 & 5.110 \\
\hline $\mathrm{Ca}(\mathrm{OH})_{2}$ & 1.596 & 0.799 & 2.469 \\
\hline $\mathrm{Fe}_{2} \mathrm{O}_{3}$ & 0.931 & 0.466 & 1.440 \\
\hline $\mathrm{K}_{2} \mathrm{CO}_{3}$ & 0.388 & 0.194 & 0.601 \\
\hline $\mathrm{Mg}(\mathrm{OH})_{2}$ & 0.503 & 0.252 & 0.778 \\
\hline $\mathrm{Th}\left(\mathrm{NO}_{3}\right)_{4} \cdot 4 \mathrm{H}_{2} \mathrm{O}$ & 5.225 & 2.617 & 8.084 \\
\hline $\mathrm{UO}_{2}\left(\mathrm{NO}_{3}\right)_{2} \cdot 6 \mathrm{H}_{2} \mathrm{O}$ & 7.716 & 3.865 & 11.938 \\
\hline $\mathrm{Na}_{2} \mathrm{Cr}_{2} \mathrm{O}_{7}$ & 0.317 & 0.159 & 0.490 \\
\hline $\mathrm{NaCl}$ & 0.418 & 0.209 & 0.646 \\
\hline $\mathrm{NaF}$ & 1.211 & 0.607 & 1.874 \\
\hline $\mathrm{Na}_{3} \mathrm{PO}_{4}$ & 1.008 & 0.505 & 1.559 \\
\hline $\mathrm{Na}_{2} \mathrm{SO}_{4}$ & 1.459 & 0.731 & 2.258 \\
\hline $\mathrm{Na}_{2} \mathrm{CO}_{3}$ & 3.559 & 1.782 & 5.506 \\
\hline TBP & 1.142 & 0.572 & 1.767 \\
\hline Total solids & 29.151 & 14.600 & 45.100 \\
\hline Added water & 70.849 & 85.400 & 54.900 \\
\hline Total sludge & 100.000 & 100.000 & 100.000 \\
\hline
\end{tabular}

${ }^{a} 100 \mathrm{ppm}$ calcium oxalate added to the surrogate sludges.

The rheology of the jetting slurries was measured with a 35A/SR12 Fann ${ }^{\mathrm{TM}}$ viscometer. Although readings were taken for the entire range of Fann ${ }^{\mathrm{TM}}$ viscometer rotation rates $(600,300,200,100,181,90$, $60,30,6,3,1.8$, and $0.9 \mathrm{rpm}$ ), the critical value was the measurement taken at $600 \mathrm{rpm}$. (The target for the in situ grout was a reading of about 150 or less; jetting slurries with readings much above 150 at 600 rpm are marginally pumpable by the high-pressure Halliburton ${ }^{\mathrm{TM}}$ HT-400 pumps used for MPI ${ }^{\mathrm{TM}}$.) Although these rotation rates and corresponding viscometer readings could be used to generate the shear rate-shear strain rheology curves for these slurries, only the readings at $600 \mathrm{rpm}$ and the 10-min gel strengths are included in this report. The 10-min gel strength is obtained after measuring the rheology by allowing the slurry to gel for $10 \mathrm{~min}$ in the viscometer and then rotating the gel and measuring the deflection reading when the gel breaks free. This reading is recorded as the 10-min gel strength in units of $\mathrm{lb}_{\mathrm{f}} / 100 \mathrm{ft}^{2}$.

The free water for sensitivity testing was measured by putting $250 \mathrm{~mL}$ of grout into a graduated cylinder and measuring the volume of free water standing over the solid grout at any given time. This property is reported as volume percent (vol \%), which is calculated by dividing the observed free water volume in milliliters by $250 \mathrm{~mL}$ and multiplying by 100 . The time interim is reported along with the volume percent of free water. The final reported value for this study was the free water after a 28-day cure. 
The density of the freshly mixed grout was obtained by measuring the net mass in grams of the $250 \mathrm{~mL}$ of grout in the free water test and dividing by $250 \mathrm{~mL}$ to obtain the density in units of grams per milliliter. The density of the surrogate sludge was also obtained using graduated cylinders. The density of the grout was measured on the freshly poured grout, before any free water segregated.

For the unconfined compressive strength, nominal 2-in. cubes of grout were cast and cured. After curing for 28 days, the cube dimensions were measured, and the force $\left(\mathrm{lb}_{\mathrm{f}}\right)$ required to crush the cube was measured on a Tinius-Olsen machine. Dividing the crushing force by the cube cross-sectional area gave the unconfined compressive strength (psi).

A modified TCLP test was performed on the grout samples after curing for 28 days in humid conditions at $30^{\circ} \mathrm{C}$. The modified procedure extracts a 10 -g sample with $200 \mathrm{~mL}$ of extractant, rather than the standard 100-g extraction with $2 \mathrm{~L}$ of extractant. The TCLP test uses one of two extractants: (1) an acetic acid solution with sodium hydroxide added (TCLP extraction fluid no. 1, pH of about 4.9) or (2) the straight acetic acid solution (TCLP extraction fluid no. 2, $\mathrm{pH}$ of about 2.9). (The procedure dictates which extractant to use based on the buffering capability of the sample when mixed with a hydrochloric acid solution.) After 18 hours of extraction, the undissolved solids are filtered from the extract and the extract is digested using a microwave digester. The concentration of inorganic RCRA metals, except mercury, in the extract are then measured using a Thermo Jarrel Ash ICAP 61E Trace Analyzer (ICP). Although selenium and arsenic analyses by ICP are not usually accepted, the U.S. Environmental Protection Agency accepts the higher sensitivity of the 61E analyzer. The concentration of mercury in the TCLP extract was measured with a Leeman Labs PS 200 cold vapor atomic absorption mercury analyzer. The only RCRA metals included in the GAAT surrogate were mercury, lead, and chromium, so only these concentrations are reported in the results. The uranium concentration is also routinely measured by the ICP; therefore, its concentration in the extract is also reported.

For the leachability index, a semidynamic leach test was performed on grout samples spiked with ${ }^{85} \mathrm{Sr}$ and ${ }^{137} \mathrm{Cs}$ and cured for 28 days in humid conditions at $30^{\circ} \mathrm{C}$ using a modification of the American National Standards Institute/American Nuclear Society (ANSI/ANS)-16.1 test. (In a semidynamic test, the samples remain quiescent in the leachate for a set time and are then moved to a fresh leachate at zero concentration for the next time interval.) The grout samples were leached in deionized water.

Concentrations of the radionuclides were measured by gamma spectroscopy using a germanium detector and a background of 30 counts per 1000 seconds or 0.03 counts per second. The germanium detector had a measured efficiency of $10 \%$ (i.e., the measured counts per second were $10 \%$ of the actual radioactive disintegrations per second). After a 30-second rinse, the leachates were changed at cumulative times of 1 , $2,3,4$, and 7 days. The effective diffusion coefficient was estimated from the cumulative fraction leached with time, assuming diffusion-controlled leaching. The leachability index is the negative of the logarithm of the effective diffusion coefficient.

\subsection{FINAL MONOLITH SENSITIVITY TESTING}

Sensitivity testing is the evaluation of the sensitivity of a selected formulation to changes in waste composition and in the concentration of the grout composition. The monolith composition (a mixture of jetting water, dry blend, preadditives, wet sludge, and supernatant) selected for sensitivity testing is listed in Table 10 (test 13, Table 7). Table 12 lists the five grout compositions used during the sensitivity testing: the standard grout formulation listed in Table 10, plus four grouts with variations in the grout composition, taken from among the $\pm 10 \%$ variation possibilities. Table 11 lists the three surrogate sludge compositions used during the sensitivity testing: the standard surrogate, the minimum water surrogate, and the maximum water surrogate. The minimum and maximum water contents were obtained from the minimum and maximum water contents listed in the measured tank sludge compositions in Table 2. For the sensitivity testing, the standard surrogate was used for the five grout compositions listed in Table 12 and the standard grout composition (grout 1, Table 12) was used for the minimum and maximum water surrogates listed in Table 11. 
Table 12. Grout compositions for testing sensitivity of the in situ grout formulation for the GAAT sludges to variations in composition

\begin{tabular}{|c|c|c|c|c|c|c|}
\hline & \multirow{2}{*}{ Component } & \multicolumn{5}{|c|}{ Composition in the final grout (wt \%) } \\
\hline & & $1^{a}$ & 2 & 3 & 4 & 5 \\
\hline \multirow{6}{*}{$\begin{array}{c}\text { Jetting } \\
\text { slurry }\end{array}$} & IRPC & 2.6 & 2.3 & 2.9 & 2.7 & 2.5 \\
\hline & Bentonite $^{b}$ & 0.8 & 0.7 & 0.9 & 0.8 & 0.7 \\
\hline & Fly ash & 8.8 & 7.7 & 9.9 & 9.1 & 8.4 \\
\hline & Slag & 9.3 & 8.1 & 10.5 & 7.9 & 10.9 \\
\hline & Cement & 4.4 & 3.8 & 4.9 & 3.7 & 5.1 \\
\hline & $\begin{array}{l}\text { Injection } \\
\text { water }\end{array}$ & 25.8 & 27.7 & 23.9 & 26.8 & 24.8 \\
\hline \multirow{2}{*}{$\begin{array}{l}\text { Preadded } \\
\text { additives }^{c}\end{array}$} & Fly ash & 5.5 & 4.8 & 6.2 & 5.7 & 5.3 \\
\hline & Slag & 5.5 & 4.8 & 6.2 & 4.7 & 6.5 \\
\hline \multirow{2}{*}{$\begin{array}{l}\text { Surrogate } \\
\text { tank } \\
\text { contents }\end{array}$} & Wet sludge & 34.5 & 37.0 & 31.9 & 35.7 & 33.1 \\
\hline & $\begin{array}{l}\text { Supernate } \\
\text { water }\end{array}$ & 2.9 & 3.1 & 2.6 & 3.0 & 2.7 \\
\hline Total & & 100.0 & 100.0 & 100.0 & 100.0 & 100.0 \\
\hline
\end{tabular}

${ }^{a}$ Standard grout selected for sensitivity testing.

${ }^{b}$ Prehydrated in mixing water before mixing with other dry blend components.

${ }^{c}$ Stabilizing additives dumped on surrogate tank contents before grout mixing.

Table 13 shows the Fann ${ }^{\mathrm{TM}}$ reading at 600 rpm for the jetting slurry, the grout density, the ratio of the grout volume to the wet surrogate sludge volume, the 28-day free water, and the 28-day unconfined compressive strength for the sensitivity testing of the in situ GAAT grout. Table 14 lists the TCLP extract concentrations for $\mathrm{Hg}, \mathrm{Pb}, \mathrm{Cr}$, and $\mathrm{U}$, plus the $\mathrm{Cs}$ and $\mathrm{Sr}$ leachability indexes measured for these same grouts. For comparative purposes, Table 14 also lists the TCLP extract concentrations of the untreated wet surrogate sludge and the TCLP extract concentration limits for the characteristic hazard, the land disposal restrictions (LDRs), and the UTSs.

Based on the Fann ${ }^{\mathrm{TM}}$ reading of 138 at $600 \mathrm{rpm}$ (Table 13), the pumpability of the jetting slurry selected for in situ grouting of the GAAT sludge (grout 1) is acceptable since the rough rule-of-thumb target was about 150 or less, as was the value of 143 for grout 1 with maximum sludge water. The jetting slurries of grouts 1, 5, and 3 (minimum sludge water) were judged to be unpumpable with values of 163 , 169 , and 231, respectively. The jetting slurry for this grout 1 (minimum sludge water) should have been about the same as for the other grout 1 formulations tested during the sensitivity test (the water content of the surrogate sludge was varied for the bottom two grouts in Table 13, not the water content of the jetting slurry). The variations tested will not be what occurs in the field (i.e., unpumpable mixes will not be pumped or jetted). In other words, this processing problem should not lead to producing an unacceptable grout in situ in the tanks but could lead to not using the jetting slurries if proper care is not taken in slurry preparation.

Minimum volume expansion was not a performance criterion for this application because the in situ grouting would be free to expand within the confines of the tanks (the sludges currently occupy only a fraction of the tank volumes). Nevertheless, the projected volume expansion was estimated (see the volume ratio in Table 13) for future reference. From Table 13, a volume increase of 150 to $200 \%$ can be 
Table 13. Results of performance testing of sensitivity of in situ GAAT grouts

\begin{tabular}{|c|c|c|c|c|c|c|c|c|c|c|}
\hline \multirow[b]{2}{*}{ Surrogate } & \multirow[b]{2}{*}{ Grout } & \multirow{2}{*}{$\begin{array}{l}\text { Fannn } \\
\text { reading at } \\
600 \mathrm{rpm}^{a}\end{array}$} & \multirow{2}{*}{$\begin{array}{l}\text { Grout } \\
\text { density } \\
(\mathrm{g} / \mathrm{mL})\end{array}$} & \multirow{2}{*}{$\begin{array}{l}\text { Volume } \\
\text { ratio of } \\
\text { grout to } \\
\text { sludge }^{b}\end{array}$} & \multirow{2}{*}{$\begin{array}{c}28 \text {-day } \\
\text { free water } \\
\text { (vol \%) }\end{array}$} & \multicolumn{5}{|c|}{ 28-day unconfined compressive strength (psi) } \\
\hline & & & & & & Sample 1 & Sample 2 & Sample 3 & Average & $\begin{array}{l}\text { Standard } \\
\text { deviation }\end{array}$ \\
\hline \multirow[t]{5}{*}{ Standard } & 1 & 138 & 1.29 & 2.75 & 0.0 & 449 & 332 & 513 & 432 & 75 \\
\hline & 2 & 75 & 1.27 & 2.61 & 0.0 & 155 & 117 & 131 & 134 & 16 \\
\hline & 3 & 231 & 1.35 & 2.84 & 0.0 & 508 & 511 & 534 & 517 & 12 \\
\hline & 4 & 114 & 1.26 & 2.72 & 0.0 & 142 & 212 & 177 & 177 & 29 \\
\hline & 5 & 169 & 1.33 & 2.78 & 0.0 & 504 & 474 & 510 & 496 & 16 \\
\hline $\begin{array}{l}\text { Maximum } \\
\text { water }\end{array}$ & 1 & 143 & 1.20 & 2.94 & 0.0 & 218 & 218 & 206 & 218 & 9 \\
\hline $\begin{array}{l}\text { Minimum } \\
\text { water }\end{array}$ & 1 & 163 & 1.39 & 2.54 & 0.0 & 514 & 467 & 375 & 452 & 58 \\
\hline
\end{tabular}

\footnotetext{
${ }^{a} \mathrm{Fann}^{\mathrm{TM}}$ viscometer reading of the jetting slurry at a rotation rate of $600 \mathrm{rpm}$
}

${ }^{b}$ Calculated from the measured wet surrogate sludge density of $1.22 \mathrm{~g} / \mathrm{mL}$, the measured grout density, and the wet sludge loading in the grout (see Table 12). 
Table 14. Results of leach testing of sensitivity of in situ GAAT grouts

\begin{tabular}{|c|c|c|c|c|c|c|c|}
\hline \multirow[b]{2}{*}{ Surrogate } & \multirow[b]{2}{*}{ Grout } & \multicolumn{4}{|c|}{ TCLP extract concentration $(\mathrm{mg} / \mathrm{L})^{a}$} & \multicolumn{2}{|c|}{ Leachability index } \\
\hline & & $\mathrm{Hg}$ & $\mathrm{Pb}$ & $\mathrm{Cr}$ & $\mathrm{U}$ & ${ }^{85} \mathrm{Sr}^{b}$ & ${ }^{137} \mathrm{Cs}^{c}$ \\
\hline \multirow[t]{5}{*}{ Standard } & 1 & 0.00007 & $<0.009$ & 0.023 & $<0.089$ & 10.4 & 11.1 \\
\hline & 2 & 0.00005 & $<0.009$ & 0.07 & $<0.089$ & 10.3 & 11.1 \\
\hline & 3 & $<0.00001$ & $<0.009$ & 0.13 & $<0.089$ & 10.6 & 11.6 \\
\hline & 4 & 0.00004 & $<0.009$ & 0.108 & $<0.089$ & 10.7 & 11.3 \\
\hline & 5 & 0.00006 & $<0.009$ & 0.092 & $<0.089$ & 10.5 & 11.4 \\
\hline $\begin{array}{l}\text { Maximum } \\
\text { water }\end{array}$ & 1 & 0.00012 & $<0.009$ & 0.079 & $<0.089$ & 10.4 & 10.9 \\
\hline $\begin{array}{l}\text { Minimum } \\
\text { water }\end{array}$ & 1 & $<0.00001$ & $<0.009$ & 0.39 & $<0.089$ & 10.3 & 11.2 \\
\hline \multicolumn{2}{|c|}{ Wet surrogate sludge } & 8.38 & 0.275 & 46.4 & 4,198 & & \\
\hline \multicolumn{2}{|c|}{$\begin{array}{l}\text { TCLP characteristic } \\
\text { limit }\end{array}$} & 0.2 & 5 & 5 & $\mathrm{NA}^{d}$ & & \\
\hline \multicolumn{2}{|c|}{ TCLP LDR limit } & 0.2 & 5 & 5 & NA & & \\
\hline \multicolumn{2}{|c|}{ TCLP UTS limit } & 0.025 & 0.37 & 0.86 & NA & & \\
\hline
\end{tabular}

${ }^{a}$ All of the grout samples were extracted with TCLP extraction fluid number 1, and the final extract $\mathrm{pH}$ was about 10; the wet surrogate sludge was extracted with TCLP fluid number 2 , and the final extract $\mathrm{pH}$ was about 6 .

${ }^{b}$ This index was measured to be 9.5 and 11.9 for the standard MVST grout and MVST grout with crystalline silicotitanate (CST) replacing IRPC, respectively.

'This index was measured to be 9.9 and 11.4 for the standard MVST grout and MVST grout with CST replacing IRPC, respectively.

${ }^{d}$ Not applicable.

expected for the wet sludge loading of 30 to $37 \mathrm{wt} \%$ projected for the in situ grouting of the tank TH-4 sludge. Tank TH-4 has the least room for volume expansion of the GAATs, restricting wet sludge loading in the grout to about $35 \mathrm{wt} \%$. The MPI ${ }^{\mathrm{TM}}$ calculations project much lower wet sludge loadings $(<10 \mathrm{wt} \%)$ for in situ grouting of the other tank sludges, with correspondingly greater volume increases, but all contained within the existing tank volumes.

No free water was observed for these grouts after curing for 28 days (Table 13). Although some free water initially appeared in the more fluid grouts, this water was reabsorbed during the 28-day cure. Some free water was projected for the large excess of water in these grouts from the surrogate sludge interstitial water, surrogate supernate (water only), and jetting water. The water to solids (W/S) ratio for the sensitivity grouts ranged from 0.9 to 1.4 (with a value of 1.1 for the standard surrogate sludge in the standard grout, that is, grout 1). Processibility (i.e., a wet, mixable paste) generally requires a W/S ratio of 0.4 to 0.6 , depending on the water demands of the sludge and dry blend. W/S ratios much higher than this range generally result in free water, unless a water-sorptive agent is used. Bentonite is an excellent water-sorptive agent, but even it was expected to be overwhelmed by the large water excess of these grouts. Apparently, designing this grout to suspend solids and resist segregation assisted in preventing free water formation by holding the solids in place long enough for the hydration reaction to encapsulate the excess water (water not absorbed by the dry blend, including bentonite) inside the grout matrix. 
Presumably, this would lead to a more porous and leachable grout; however, these grouts exhibited excellent leach resistance (Table 14). As with the volume increase, free water was not a performance concern for the projected in situ grouting. As stated previously, free water was expected and would have been handled as sludge supernatant is handled (e.g., it would be pumped into the MVST tanks). Lack of free water is considered a bonus for the grout injected using the MPI ${ }^{\mathrm{TM}}$ process. Although bentonite proved an excellent ingredient for this sensitivity testing, these results may not necessarily extrapolate to other tank sludges with higher concentrations of dissolved salts than the GAAT surrogate because of the sensitivity of bentonite's water-sorptive properties to salt solutions.

The 28-day unconfined compressive strength of the sensitivity grouts ranged from 117 to $534 \mathrm{psi}$, more than enough to support anticipated overburdens associated with grouting these sludges in situ and leaving the grout in the tanks. U.S. Nuclear Regulatory Commission (NRC) and RCRA caps require unconfined compressive strengths of 50 to 60 psi for overburden support. ${ }^{6}$

Figures 13 through 16 illustrate the leaching of ${ }^{85} \mathrm{Sr}$ and ${ }^{137} \mathrm{Cs}$ with time from the sensitivity test grouts for in situ grouting of the GAAT sludges. Triplicate samples (1A, 1B, and 1C) of the standard grout (grout 1) with the standard surrogate were leached. Single samples of the other grouts $(2,3,4$, and 5 ) with the standard surrogate were leached, as well as grout 1 with minimum and maximum water (min water and max water). Less than $2.5 \%$ of these radioisotopes leached from these small grout cylinders during 1 week. These leach curves exhibit little scatter among them, resulting in the small range of leachability indexes calculated from these data: 10.3 to 10.7 and 10.9 to 11.6 for ${ }^{85} \mathrm{Sr}$ and ${ }^{137} \mathrm{Cs}$, respectively (Table 14). In general, these leachability indexes are excellent for these relatively soluble radioisotopes. The NRC performance criteria recommend leachability indexes of $>6.0$; hence, the leach resistance of these grouts exceeds the NRC minimum by four orders of magnitude (in terms of the effective diffusion coefficient). ${ }^{6}$ Figures 17 and 18 compare the leaching performance of the in situ GAAT grout with two grouts used to stabilize surrogate MVST sludge. One of the MVST grouts contains IRPC to stabilize ${ }^{137} \mathrm{Cs}$, the same as the GAAT grout, and the other contains crystalline silicotitanate (CST) instead of IRPC. The standard MVST grout consisted of 3.6, 9.0, 8.6, 14.9, 9.0, and $55.0 \mathrm{wt} \%$ of IRPC, perlite, fly ash, slag, cement, and surrogate MVST sludge, respectively. The grout with CST had the same composition except for the substitution of CST for IRPC. As illustrated in Figs. 17 and 18, the GAAT grout was more leach resistant than the MVST grout, but CST significantly improved the leach resistance of the MVST grout. The corresponding leachability indexes for ${ }^{85} \mathrm{Sr}$ and ${ }^{137} \mathrm{Cs}$, respectively, were 9.5 and 9.9 for the standard MVST grout and 11.9 and 11.4 for the CST MVST grout, compared with 10.3 to 10.7 and 10.9 to 11.6 for the GAAT sensitivity grouts. Although CST apparently confers superior leach resistance to a grout, the GAAT grouts with IRPC exhibited excellent leach resistance that is more than adequate for the in situ grouting of the GAAT sludges.

Although the GAAT sludges are purportedly only characteristically hazardous for $\mathrm{Hg}$, the surrogate GAAT sludge was characteristically hazardous for both $\mathrm{Hg}$ and $\mathrm{Cr}$ (Table 14). Presumably, the conservative use of soluble sodium dichromate in the surrogate led to this discrepancy. As for lead, the other RCRA metal included in the surrogate recipe, not only was the lead concentration in the TCLP extract of the surrogate GAAT sludge below the characteristic limit, but it was also below the TCLP LDR and UTS limits. Thus, the surrogate was hazardous by TCLP for $\mathrm{Hg}$ and $\mathrm{Cr}$ but not $\mathrm{Pb}$. The concentration of all three RCRA metals in the TCLP extract was greatly reduced for the treated surrogate (i.e., the GAAT grouts) and did not prove sensitive to the variations tested in grout and surrogate composition (Table 14). The range of ratios of untreated to treated TCLP extract concentrations were 69,833 to >838,000 for $\mathrm{Hg},>31$ for $\mathrm{Pb}$, and 119 to 2,017 for $\mathrm{Cr}$. Thus, stabilization of the surrogate GAAT sludge in the in situ GAAT grout decreased the TCLP extract concentration by more than a factor of 60,000 for $\mathrm{Hg}, 30$ for $\mathrm{Pb}$, and 100 for $\mathrm{Cr}$. In addition, the TCLP extract concentration of uranium decreased from 4,198 to $<0.089 \mathrm{mg} / \mathrm{L}$, a reduction factor of more than 40,000 . The extract uranium concentration is undoubtedly related to the final $\mathrm{pH}$ of the extracts, which were 6 for the untreated surrogate sludge and about 10 for the sensitivity grouts. 


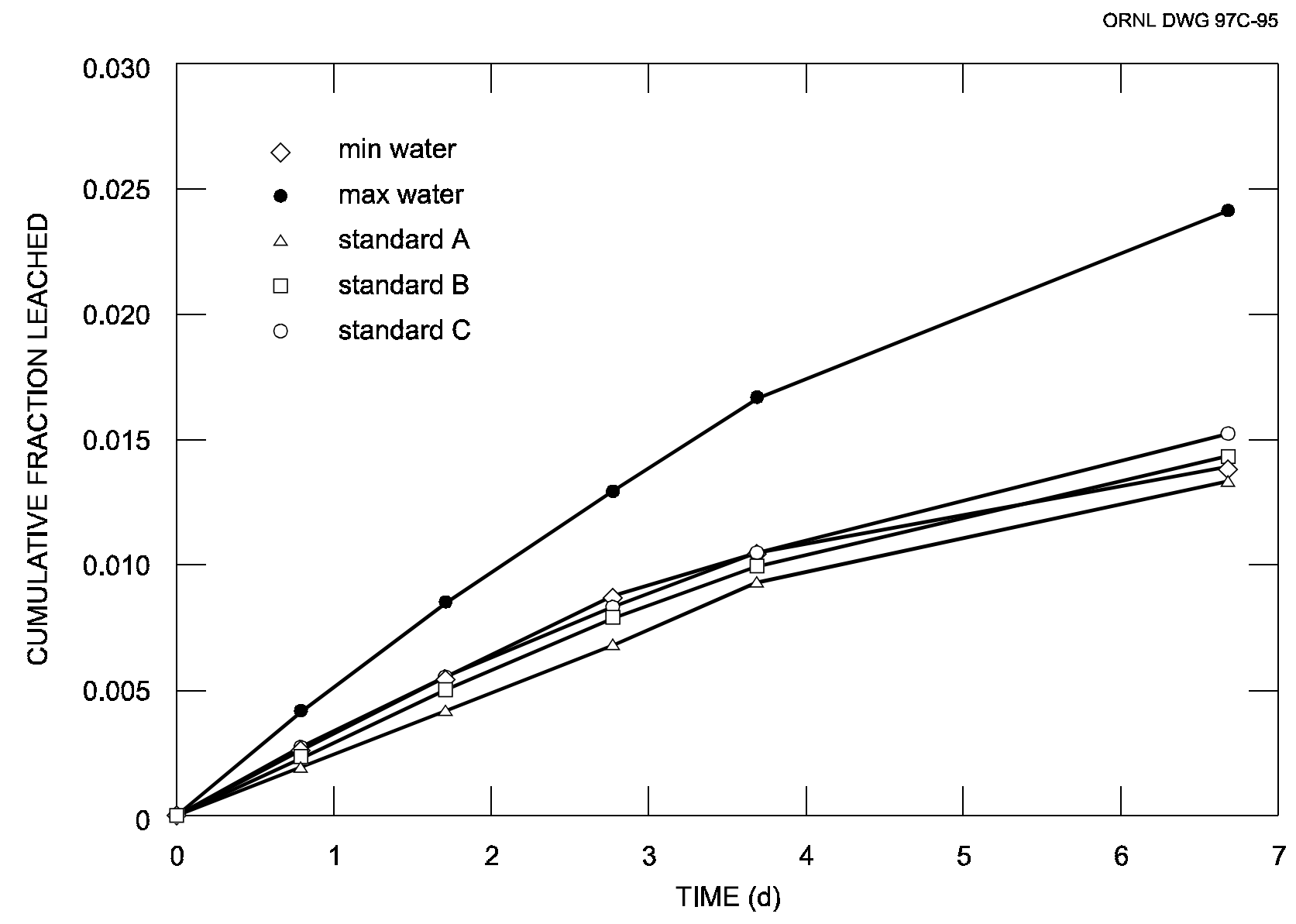

Fig. 13. Strontium-85 leaching with time for the standard in situ GAAT grout (grout 1 in Table 12). 


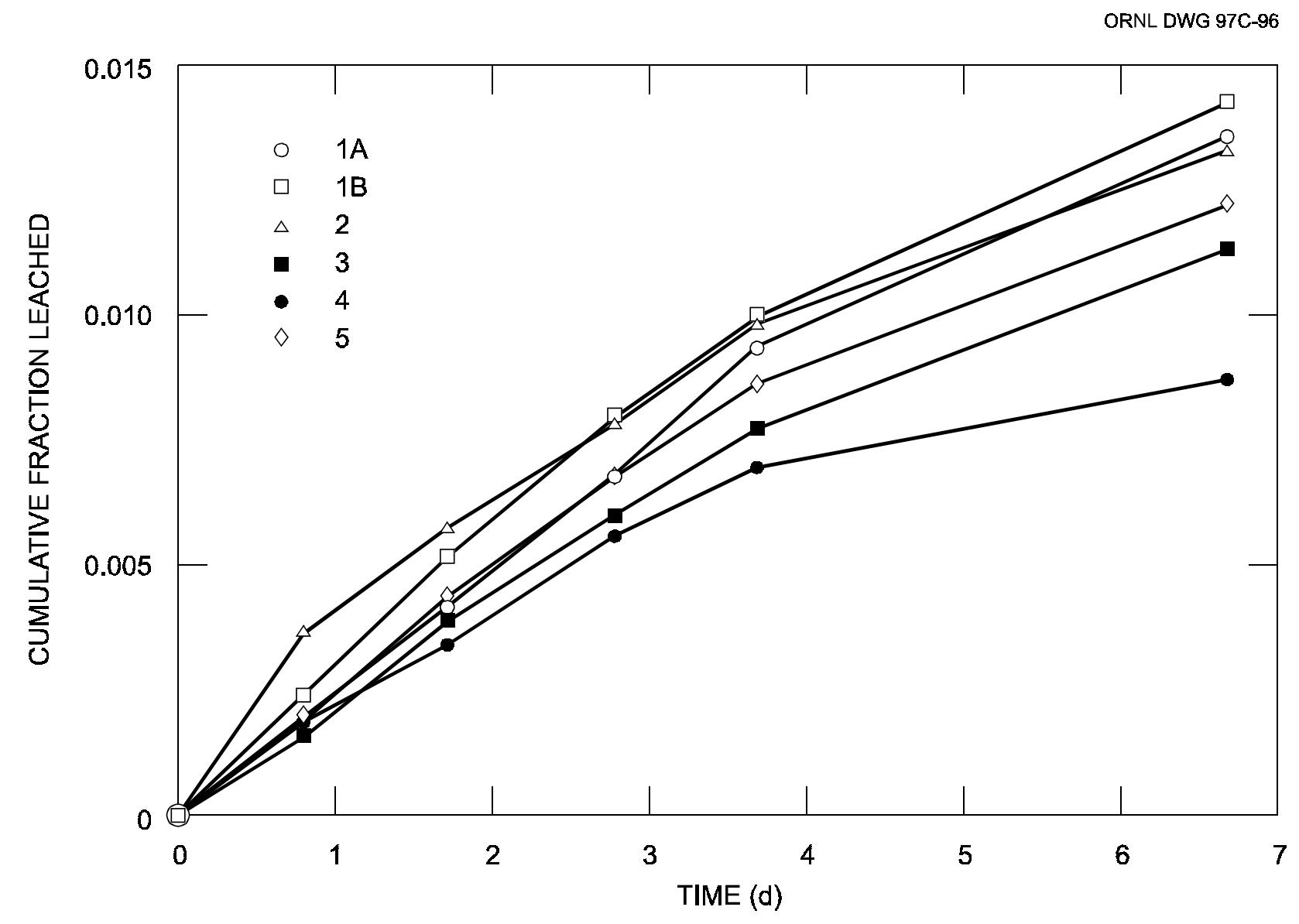

Fig. 14. Strontium-85 leaching with time for the sensitivity in situ GAAT grouts. 


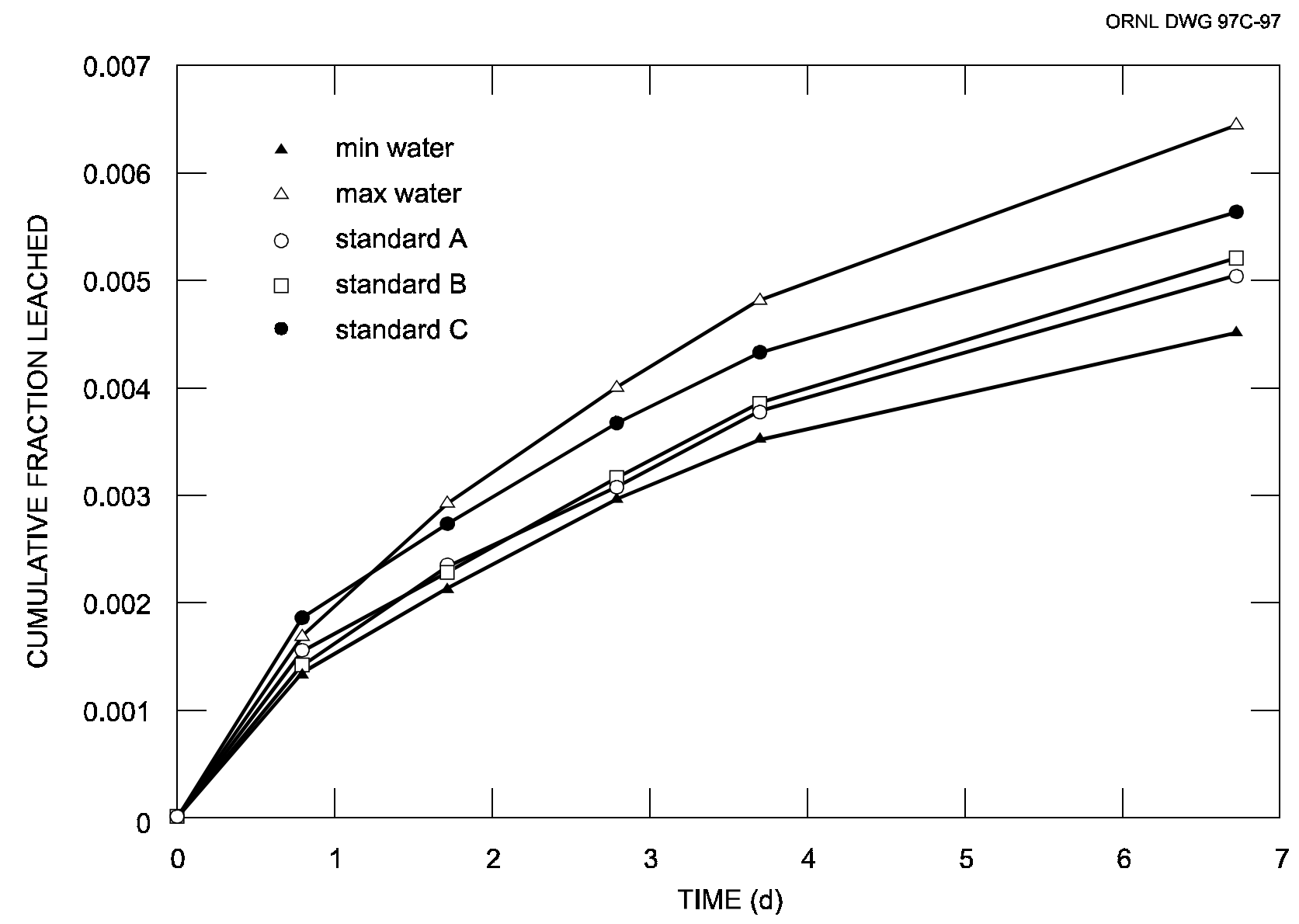

Fig. 15. Cesium-137 leaching with time for the standard in situ GAAT grout (grout 1 in Table 12). 


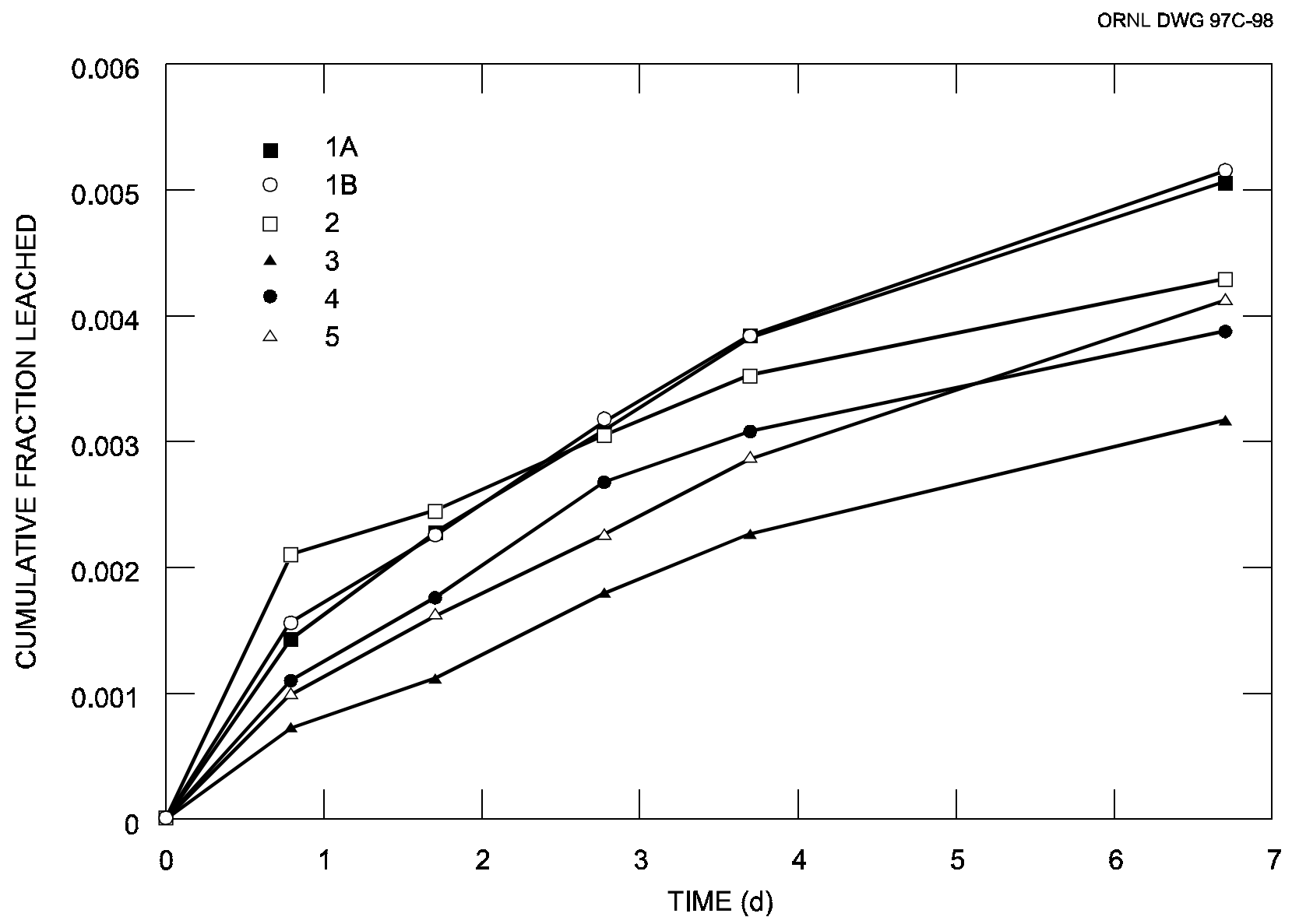

Fig. 16. Cesium-137 leaching with time for the sensitivity in situ GAAT grouts. 


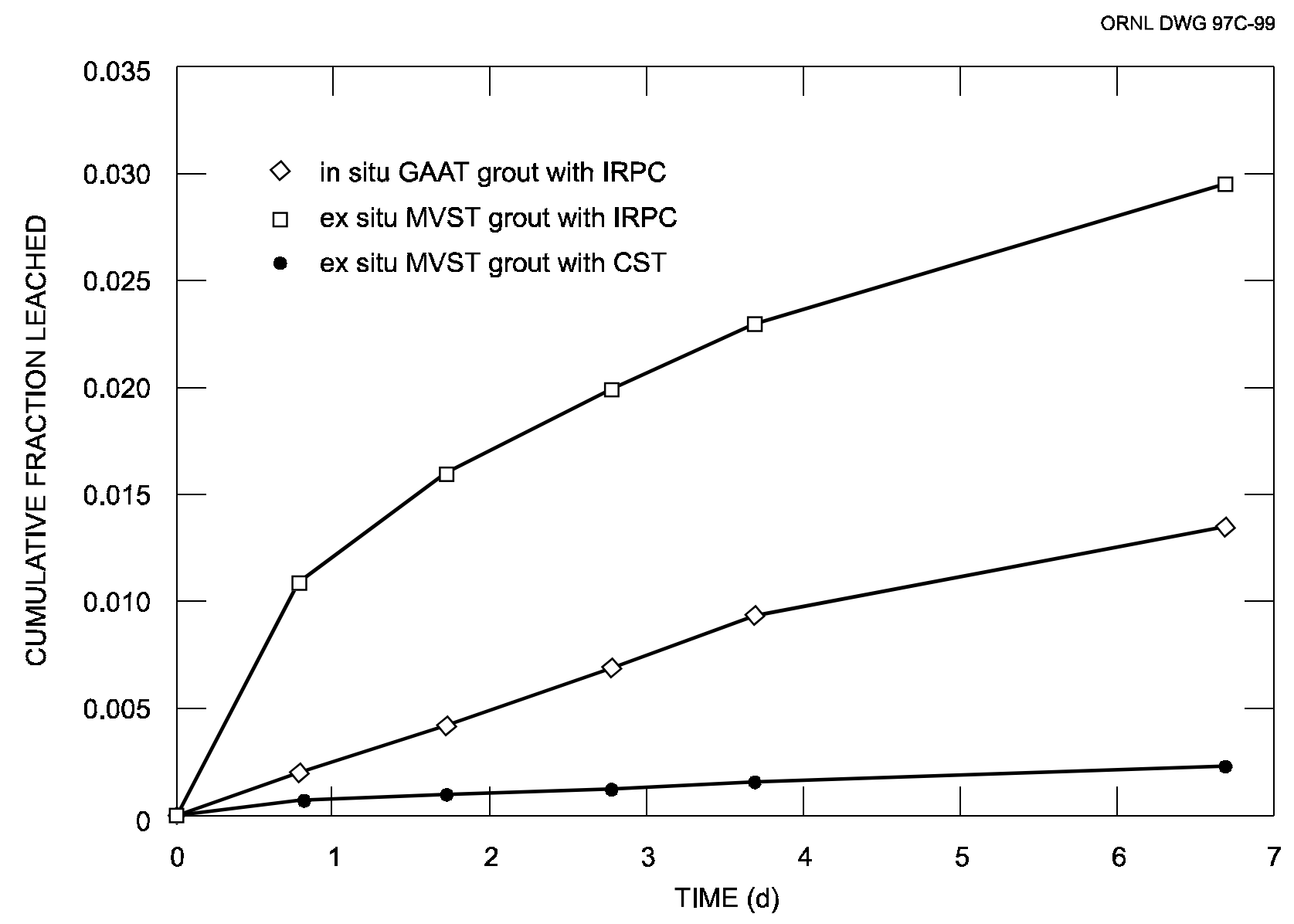

Fig. 17. Comparison of leach results for ${ }^{85} \mathrm{Sr}$ among GAAT, MVST, IRPC, and CST. 
ORNL DWG 97C-100

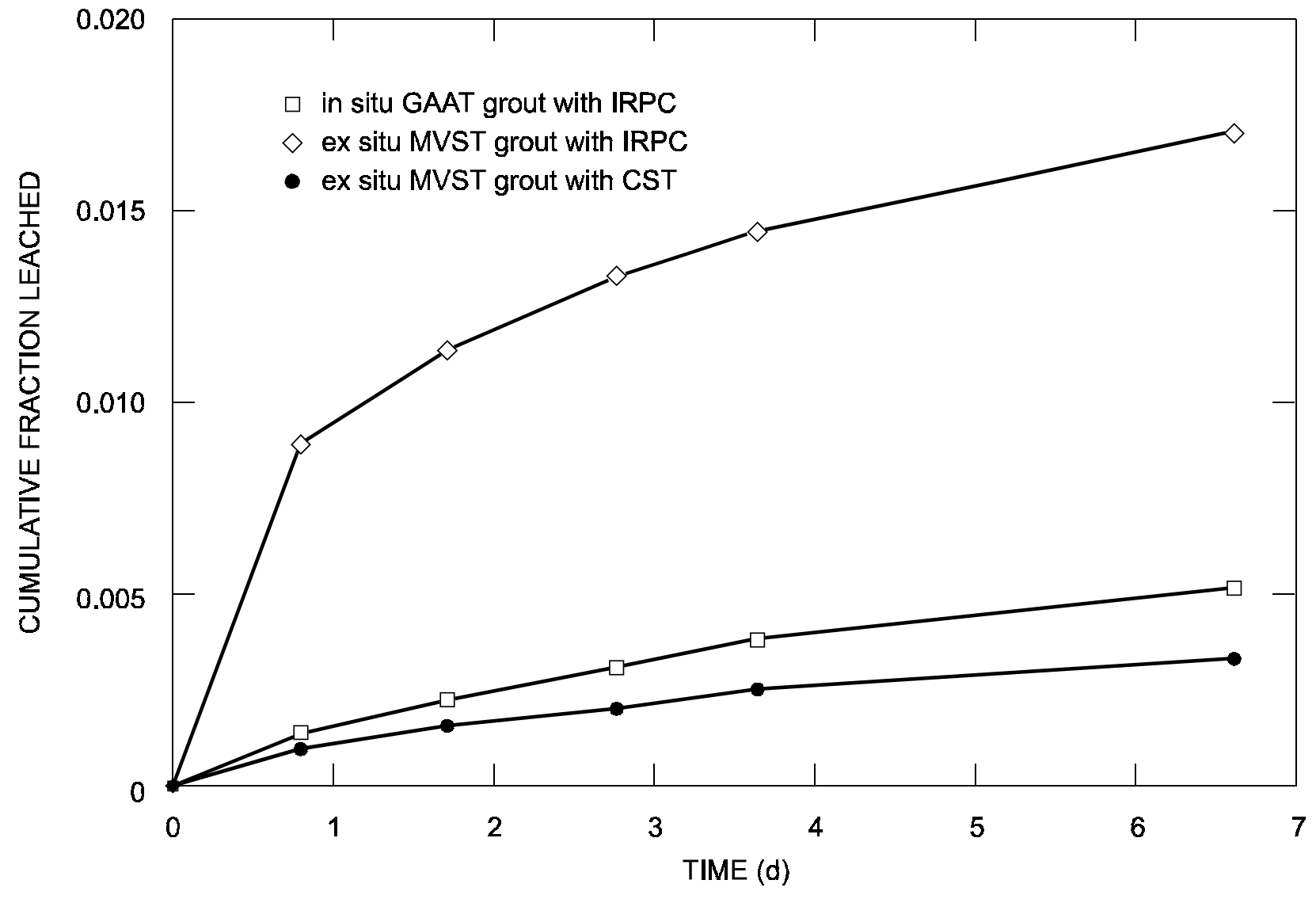

Fig. 18. Comparison of leach results for ${ }^{137}$ Cs among GAAT, MVST, IRPC, and CST. 


\section{COST DATA}

A very preliminary cost estimate was performed for conducting the MPI ${ }^{\mathrm{TM}}$ process. Based on the volumes for injecting tank W-10 (a 50-ft-diam GAAT), this cost evaluation was done before the development of the grout program cited in this report. The major activities and associated costs are shown in Table 15.

Table 15. Estimated cost for MPI ${ }^{\mathrm{TM}}$ solidification of one 50-ft-diam Gunite ${ }^{\mathrm{TM}} \operatorname{tank}^{a}$

\begin{tabular}{lc}
\hline \multicolumn{1}{c}{ Activity } & Cost (\$) \\
\hline Hand dig and install augers in 15 holes & 10,000 \\
High-density polyethylene plastic liner plus tips & 3,000 \\
Diposable high-pressure hoses and MPI ${ }^{\mathrm{TM}}$ monitors & 43,000 \\
Preventers, pulleys, cables, and disposables & 10,000 \\
High-pressure pumping services, Haliburton (mobilization and demobilization of all & 50,190 \\
pumps, valves, labor, etc.) & \\
120 tons of dry blend (slag, cement, fly ash) & 10,200 \\
Total direct cost & $\mathbf{1 2 6 , 3 9 0}$ \\
MK Ferguson Construction Management (40\% direct cost) & 50,500 \\
Total direct cost + management & $\mathbf{1 7 6 , 8 9 0}$ \\
MPI ${ }^{\mathrm{TM}}$ license fee & 20,000 \\
Engineering support, health physics, training, security & 300,000 \\
Total estimated cost for MPI ${ }^{\mathrm{TM}}$ solidification of one 50-ft-diam Gunite & \\
\hline
\end{tabular}

${ }^{a}$ Adapted with permission from J. L. Kauschinger, Utilization of the MPI TM Process For In-Tank Solidification Of Gunite Tank Bottom Sludge at WAG 1, Ground Environmental Services, Inc., Alpharetta, Ga., January 1997 (report not available for public release). 


\section{SUMMARY AND CONCLUSIONS}

Based on the work with the surrogate sludges, in situ grouting of the GAAT sludges by MPI ${ }^{\mathrm{TM}}$ can produce grouts with little or no free water that are resistant to solids segregation, that stabilize the RCRA metals within TCLP limits, and that provide excellent leach resistance for the radionuclides. These results must be confirmed with actual hot sludge before final acceptance of this approach. The tank sludges can be stabilized at a wet sludge loading of $37 \mathrm{wt} \%$, or less, resulting in a volume increase of $150 \%$, or more, with little or no secondary waste generation. The grout strength is relatively low at 100 to 500 psi but is more than strong enough to support anticipated overburdens. A strong monolithic solid is not usually a waste acceptance criterion, although a monolith does decrease the surface area available for leaching and consequently improves leach resistance. Grouts can stabilize the RCRA metals, including mercury, a potential problem species for the tank sludges, and pass the TCLP test. The grout selected for sensitivity testing decreased the concentrations of $\mathrm{Hg}, \mathrm{Pb}$, and $\mathrm{Cr}$ in the TCLP extract by orders of magnitude. Despite the high water content, the selected grouts exhibited excellent leach resistance, with ${ }^{85} \mathrm{Sr}$ and ${ }^{137} \mathrm{Cs}$ leachability indexes in excess of 10 .

None of the properties of this grout proved sensitive to the variations in grout and surrogate sludge compositions tested except for the pumpability of the jetting slurry. Designing the grout to resist settling of solids made it borderline in the objective test of pumpability. Further refinement or testing may be required to ensure that the designated jetting slurry is pumpable during application of MPI ${ }^{\mathrm{TM}}$ in situ grouting of the tank sludges. A small field test with full-scale equipment is suggested before actual tank remediation. Pumping the proposed jetting slurry through the full-scale equipment is quite different from the laboratory mixing and testing and will reveal any pumping difficulties. If such pumping difficulties exist, then further refinements can be made to the grout formulation.

The preferred grout formulation is listed as grout 1 in Table 12 . The mixing procedure to produce 1 $\mathrm{kg}$ of grout consists of the following steps, which produce the final monolithic structure shown in Table 10 .

1. Prehydrating $8 \mathrm{~g}$ of bentonite in $258 \mathrm{~g}$ of injection water to form the bentonite slurry.

2. Blending together the dry ingredients: IRPC (26 g), fly ash (88 g), slag (93 g), and cement (44 g).

3. Mixing the bentonite slurry with the dry ingredients to form the jetting slurry.

4. Dumping $55 \mathrm{~g}$ of fly ash and $55 \mathrm{~g}$ of slag on the jetting slurry and wet sludge mixture without mixing them in.

5. Mixing the jetting slurry with the wet sludge and pre-added fly ash and slag.

The cost for MPI ${ }^{\mathrm{TM}}$ solidification of one 50 -ft-diam Gunite ${ }^{\mathrm{TM}}$ tank is estimated at $\$ 500 \mathrm{~K}$. 


\section{REFERENCES}

1. W. de Laguna et al., Engineering Development of Hydraulic Fracturing as a Method for Permanent Disposal of Radioactive Wastes, ORNL-4259, Union Carbide Corp., Oak Ridge Natl. Lab., August 1968.

2. Multi-point injection ${ }^{\mathrm{TM}}$ Demonstration for Solidification of Shallow Buried Waste at Oak Ridge Reservation, Oak Ridge, Tennessee, ORNL/ER-378, prepared by Ground Environmental Services, Inc., for Lockheed Martin Energy Research Corp., Oak Ridge Natl. Lab., October 1996.

3. Evaluation of Phase I and Phase II Sampling and Analysis Data for the Gunite ${ }^{\mathrm{TM}}$ and Associated Tanks at Oak Ridge National Laboratory, Oak Ridge, Tennessee, ORNL/ER-365, prepared by MACTEC for Lockheed Martin Energy Research Corp., Oak Ridge Natl. Lab., March 1996.

4. J. L. Kauschinger, "Workplan for the Demonstration of the Multi-point injection" System for Solidification of the GAAT Tank Sludge," January 1997.

5. 10 CFR Pt. 61, U.S. Nuclear Regulatory Commission, "Licensing Requirements for Land Disposal of Radioactive Waste." 
ORNL/TM-13389

INTERNAL DISTRIBUTION

$\begin{aligned} \text { 1. } & \text { L. V. Asplund } \\ \text { 2. } & \text { B. L. Burks } \\ \text { 3. } & \text { T. B. Conley } \\ \text { 4. } & \text { T. M. Gilliam } \\ 5 . & \text { D. D. Huff } \\ 6 . & \text { T. E. Kent } \\ 7 . & \text { J. W. Kubarewicz } \\ 8 \text {-9. } & \text { B. E. Lewis* } \\ \text { 10. } & \text { J. M. Lynch }\end{aligned}$
11. C. H. Mattus
12. E. W. McDaniel ${ }^{*}$
13. L. E. McNeese
14. S. R. Robinson
15-24. R. D. Spence*
25-29. S. D. Van Hoesen*
30. Central Research Library*
31. Lab Records-RC
32-33. Lab Records-OSTI

\section{EXTERNAL DISTRIBUTION}

34-43. J. L. Kauschinger, Ground Environmental Sciences, Inc., 200 Berry Glen Court, Alpharetta, GA 30202*

*Indicates distribution of paper copies. All other distribution is through the World Wide Web at http://www.ornl.gov/divisions/ctd/Eng_Dev/publications.htm and at http://www.ornl.gov/Library/ ORNL_reports.html. 